BNL-52594

Formal Report

\title{
Thermoplastic Encapsulation Treatability Study of Fernald Silo 1 and Silo 3 Wastes
}

\author{
P.R. Lageraaen, J.W. Adams, L.W. Milian, P.D. Kalb \\ BROOKHMVEN \\ NATIONAL LABORATORY
}

May 1998

Environmental Sciences Department

Brookhaven National Laboratory

Brookhaven Science Associates

Upton, Long Island New York 11973

Under Contract No. DE-AC02-98CH10886 with the

UNITED STATES DEPARTMENT OF ENERGY 


\section{DISCLAIMER}

This report was prepared as an account of work sponsored by an agency of the United States Government. Neither the United State Government nor any agency thereof, nor any of their employees, not any of their contractors, subcontractors, or their employees, makes any warranty, express or implied, or assumes any legal liability or responsibility for the accuracy, completeness, or usefulness of any information, apparatus, product, or process disclosed, or represents that its use would not infringe privately owned rights. Reference herein to any specific commercial product, process, or service by trade name, trademark, manufacturer, or otherwise, does not necessarily constitute or imply its endorsement, recommendation, or favoring by the United States Government or any agency, contractor, or subcontractor thereof. The vies and opinions of authors expressed herein do not necessarily state or reflect those of the United States Government or any agency, contractor or subcontractor thereof.

Printed in the United States of America

Available from

National Technical Information Service

U.S. Department of Commerce

5285 Port Royal Road

Springfield, VA 22161 


\title{
Thermoplastic Encapsulation Treatability Study of Fernald Silo 1 and Silo 3 Wastes
}

P.R. Lageraaen, J.W. Adams, L.W. Milian, P.D. Kalb

May 1998

Prepared by:

Environmental \& Waste Technology Center

Department of Advanced Technology

Brookhaven National Laboratory

\author{
Prepared for: \\ Mixed Waste Focus Area \\ Office of Science and Technology \\ United States Department of Energy \\ Contract No. DE-AC02-98CH10886
}

'This work was performed under the auspices of the U.S. Department of Energy. 


\begin{abstract}
Treatability studies for polyethylene and sulfur polymer microencapsulation of Fernald Silo 1 and Silo 3 wastes were conducted at Brookhaven National Laboratory (BNL). The treatability work, which included optimal formulation development and processibility testing, was performed to determine the applicability of these solidification technologies for the Fernald Silo mixed wastes. A surrogate was used during formulation development for the Silo 1 waste. Processing results in conjunction with leach testing of waste forms to measure waste form performance were used to establish the most effective thermoplastic/waste composition. A series of waste form specimens were cast from the surrogate and mixed waste encapsulated product with both polyethylene and sulfur polymer for more comprehensive testing at the University of Cincinnati. This data will be compared with treatability results from alternative solidification and stabilization methods such as cementation and phosphate-bonded ceramics, to evaluate treatment options for Fernald Silo wastes. Based on the treatability results, polyethylene and sulfur polymer microencapsulation can successfully process Silo wastes. Considering waste form leach performance using the Universal Treatment Standard limits, based on testing conducted at BNL, polyethylene and sulfur polymer are both viable treatment methods for Silo 3 waste. For Silo 1 waste, polyethylene microencapsulation is recommended due to the high lead concentration in the waste.
\end{abstract}




\section{TABLE OF CONTENTS}

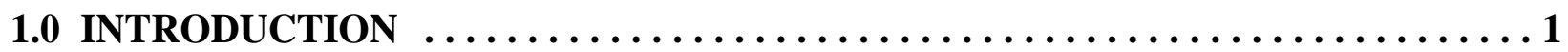

2.0 TECHNOLOGY DESCRIPTION $\ldots \ldots \ldots \ldots \ldots \ldots \ldots \ldots \ldots \ldots \ldots \ldots \ldots \ldots$

2.1 Polyethylene Microencapsulation $\ldots \ldots \ldots \ldots \ldots \ldots \ldots \ldots \ldots \ldots \ldots \ldots$

2.2 Sulfur Polymer Microencapsulation $\ldots \ldots \ldots \ldots \ldots \ldots \ldots \ldots \ldots \ldots \ldots$

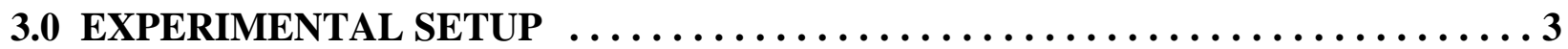

3.1 Silo 1 Surrogate Waste .............................

3.1.1 Polyethylene Microencapsulation of Silo 1 Surrogate Waste . . . . . 3

3.1.2 SPC Microencapsulation of Silo 1 Surrogate Waste . . . . . . . . . 5

3.2 Silo 1 Actual Waste $\ldots \ldots \ldots \ldots \ldots \ldots \ldots \ldots \ldots \ldots \ldots \ldots \ldots \ldots$

3.2.1 Polyethylene Microencapsulation of Silo 1 Actual Waste . . . . . . . 9

3.2.2 SPC Encapsulation of Silo 1 Actual Waste $\ldots \ldots \ldots \ldots \ldots \ldots \ldots$.

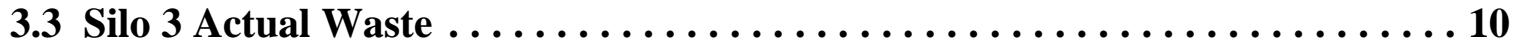

3.3.1 Polyethylene Microencapsulation of Silo 3 Actual Waste ........ 10

3.3.2 SPC Microencapsulation of Silo 3 Actual Waste ........... 10

4.0 EXPERIMENTAL RESULTS $\ldots \ldots \ldots \ldots \ldots \ldots \ldots \ldots \ldots \ldots \ldots \ldots \ldots \ldots \ldots$

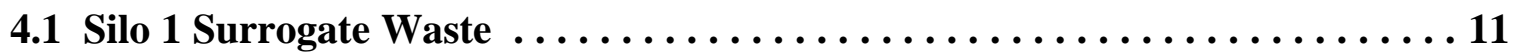

4.1.1 Polyethylene Microencapsulation of Silo 1 Surrogate Waste ...... 11

4.1.2 SPC Microencapsulation of Silo 1 Surrogate Waste $\ldots \ldots \ldots \ldots \ldots 17$

4.2 Silo 1 Actual Waste ................................ 21

4.2.1 Polyethylene Microencapsulation of Silo 1 Actual Waste ........21

4.2.2 SPC Microencapsulation of Silo 1 Actual Waste $\ldots \ldots \ldots \ldots \ldots 25$

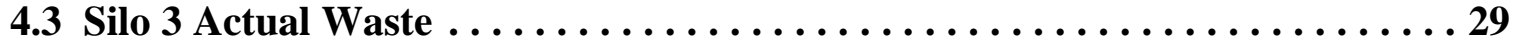

4.3.1 Polyethylene Microencapsulation of Silo 3 Actual Waste ........ 29

4.3.2 SPC Microencapsulation of Silo 3 Actual Waste ............ 35

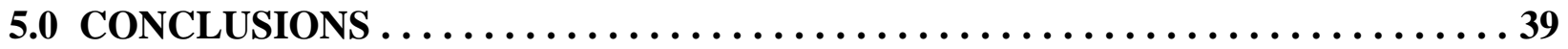

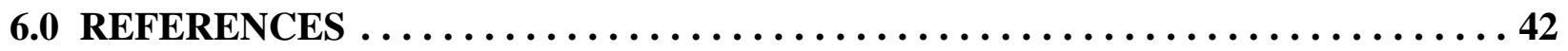




\section{LIST OF FIGURES}

Figure 3.1. Photograph of Lex 100 Kinetic Mixer at BNL and Containment Enclosure . 4

Figure 3.2. $\quad$ Ross Double Planetary Mixer used to dry waste and process large SPC batches ................................. 5

Figure 3.3. Small-batch $S P C$ process equipment $\ldots \ldots \ldots \ldots \ldots \ldots \ldots \ldots \ldots \ldots \ldots$

Figure 3.4. Large-batch $\mathrm{SPC}$ process equipment $\ldots \ldots \ldots \ldots \ldots \ldots \ldots \ldots \ldots \ldots \ldots$

Figure 3.5. Photograph of Extruder and Feeders Used to Process Silo 1 Actual Waste .. 9

Figure 4.1. LDPE and Silo 1 Surrogate Waste Form Specimens Prepared for FDF . . 15

Figure 4.2. SPC and Silo 1 Surrogate Waste Form Specimens Prepared for FDF . . . . 19

Figure 4.3. Extrusion Processing of Silo 1 Actual Waste During Fabrication of $2 \times 4$ in. Waste Form Specimens . . . . . . . . . . . . . . . 22

Figure 4.4. LDPE and Silo 1 Actual Waste Form Specimens Prepared for FDF . . . . 22

Figure 4.5. Photograph of a SPC/Silo 1 Waste Batch Being Poured Into a

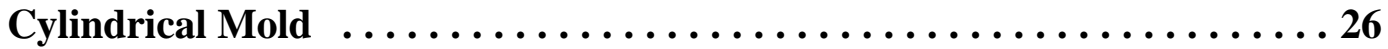

Figure 4.6. SPC and Silo 1 Actual Waste Form Specimens Prepared for FDF $\ldots \ldots 26$

Figure 4.7. LDPE and Silo 3 Waste Form Specimens Prepared for FDF . . . . . . . 32

Figure 4.8. SPC and Silo 3 Waste Form Specimens Prepared for FDF $\ldots \ldots \ldots \ldots$ 


\section{LIST OF TABLES}

Table 4.1. Summary of LDPE Microencapsulation Kinetic Mixer Processibility

Testing with Silo 1 RCRA Surrogate .................... 12

Table 4.2. LDPE Microencapsulation Kinetic Mixer TCLP Leach Results (mg/l) for Silo1 Surrogate ........................... 13

Table 4.3. LDPE Microencapsulated Silo 1 Surrogate $2 \times 4$ in. Cylindrical Specimens . 15

Table 4.4. LDPE Microencapsulated Silo 1 Surrogate 1x1 in. Cylindrical Specimens . 16

Table 4.5. LDPE Microencapsulated Silo 1 Surrogate 1x2 in. Cylindrical Specimens . 16

Table 4.6. LDPE Microencapsulated Silo 1 Surrogate $2 \times 2 \times 2$ in. Cubic Specimens $\ldots 17$

Table 4.7. TCLP Lead Concentrations (mg/l) for SPC/Silo 1 Surrogate

Test Formulations ............................... 18

Table 4.8. SPC Microencapsulated Silo 1 Surrogate 2x4 in. Cylindrical Specimens .. 19

Table 4.9. SPC Microencapsulated Silo 1 Surrogate 1x1 in. Cylindrical Specimens .. 20

Table 4.10. SPC Microencapsulated Silo 1 Surrogate 1x2 in. Cylindrical Specimens .. 20

Table 4.11. SPC Microencapsulated Silo 1 Surrogate $2 \times 2 \times 2$ in. Cubic Specimens ..... 21

Table 4.12. LDPE Encapsulated Silo 1 Waste $2 \times 4$ in. Cylindrical Specimens $\ldots \ldots \ldots 23$

Table 4.13. LDPE Encapsulated Silo 1 Waste 1x1 in. Cylindrical Specimens $\ldots \ldots .23$

Table 4.14. LDPE Encapsulated Silo 1 Waste 1x2 in. Cylindrical Specimens ...... 24

Table 4.15. LDPE Encapsulated Silo 1 Waste $2 \times 2 \times 2$ in. Cubic Specimens ......... 25

Table 4.16. SPC Microencapsulated Silo 1 Waste $2 \times 4$ in. Cylindrical Specimens $\ldots \ldots 27$

Table 4.17. SPC Microencapsulated Silo 1 Waste 1x1 in. Cylindrical Specimens $\ldots . .27$

Table 4.18. SPC Microencapsulated Silo 1 Waste 1x2 in. Cylindrical Specimens $\ldots \ldots 28$

Table 4.19. SPC Microencapsulated Silo 1 Waste $2 \times 2 \times 2$ in. Cubic Specimens . . . . . . 29

Table 4.20. Summary of Processibility Testing with Polyethylene and Silo 3

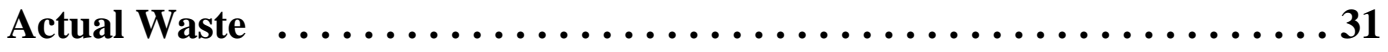

Table 4.21. TCLP Leach Results (mg/l) for LDPE and Silo 3 Waste Forms ......... 31

Table 4.22. LDPE Encapsulated Silo 3 Waste $2 \times 4$ in. Cylindrical Specimens .......33

Table 4.23. LDPE Encapsulated Silo 3 Waste 1x1 in. Cylindrical Specimens .......33

Table 4.24. LDPE Encapsulated Silo 3 Waste 1x2 in. Cylindrical Specimens ....... 34

Table 4.25. LDPE Encapsulated Silo 3 Waste $2 \times 2 \times 2$ in. Cubic Specimens .......... 35

Table 4.26. TCLP Concentrations (mg/l) for SPC/Silo 3 Test Formulations . . . . . 36

Table 4.27. SPC Encapsulated Silo 3 Waste $2 \times 4$ in. Cylindrical Specimens . . . . . . . 37

Table 4.28. SPC Encapsulated Silo 3 Waste 1x1 in. Cylindrical Specimens ......... 37

Table 4.29. SPC Encapsulated Silo 3 Waste 1x2 in. Cylindrical Specimens ........ 38

Table 4.30. SPC Encapsulated Silo 3 Waste $2 \times 2 \times 2$ in. Cubic Specimens .......... 39 


\subsection{INTRODUCTION}

A treatability study was conducted for polyethylene and sulfur polymer microencapsulation of Fernald Silo 1 and Silo 3 wastes. Polyethylene and sulfur polymer are thermoplastics developed for waste encapsulation at BNL. These materials have been considered as potential treatment alternatives for Fernald Silo wastes. Treatability work with polyethylene and sulfur polymer was initiated with a Silo 1 surrogate, prepared by Fluor Daniel Fernald (FDF), to optimize process parameters and determine best formulations for waste form performance. Once effective formulations were developed with the surrogate, confirmation processing was conducted using actual Silo 1 waste. A surrogate was not available for Silo 3, so all treatability work including formulation development was performed with the actual Silo 3 waste.

Formulation development with polyethylene and sulfur polymer consisted of processing varying mixture compositions, preparing test specimens and conducting waste form performance testing. Processibility was also a consideration in gauging the success of a formulation. Performance testing was limited to leach testing, performed in accordance with the Toxicity Characteristic Leaching Procedure (TCLP).[1] Mechanical integrity testing was not conducted at BNL while developing optimal formulations because compressive strength of polyethylene and sulfur polymer waste forms is known by experience to exceed minimum strength requirements, as specified by the NRC for licensable solidification processes. However, various samples were prepared for subsequent testing and performance evaluation by the University of Cincinnati (UC).

\subsection{TECHNOLOGY DESCRIPTION}

\subsection{Polyethylene Microencapsulation}

Polyethylene microencapsulation is a well demonstrated and documented waste encapsulation technology with wide waste-type applicability. $[2,3,4,5,6,7,8,9,10,11,12]$ Polyethylene provides durable waste forms and is inert so waste and binder incompatibilities do not occur. Processing simply requires heating the polyethylene above its melting point (approximately $120^{\circ} \mathrm{C}$, although processing may occur up to $50^{\circ} \mathrm{C}$ above this) and mixing the waste with the viscous polymer melt. Processing can be accomplished through the use of kinetic mixing or extrusion. These represent two alternative processing methods for polyethylene waste encapsulation. Both processing methods were tested during this investigation.

Extrusion is the conventional processing method developed and patented at BNL for polyethylene microencapsulation.[13] As a continuous process, waste and polymer are accurately metered to the extruder in which a rotating auger screw conveys the material through a heated barrel. Shear, friction, and external heating melts the polymer. The screw, which may incorporate numerous designs, mixes the molten polymer with the waste, builds 
pressure and pumps the molten material through a die. The molten extruder product, known as extrudate, can be molded or collected in a final waste container. Cooling of the extrudate results in a solid monolithic waste form.

Kinetic mixing is a batch process using high-shear and rapid rotational motion to melt thermoplastics and thoroughly homogenize mixtures of waste and polymer. This technology (patent pending) was recently developed by BNL and EcoLEX, Inc. under a DOE Mixed Waste Focus Area Cooperative Research and Development Agreement. Previous research and development results demonstrated the ability to successfully process wastes containing moisture and particle sizes exceeding those deemed acceptable for extrusion. Kinetic mixers do not contain heaters so melting thermoplastics is accomplished entirely through frictional heat generation. Cycle times in the kinetic mixer are dependent on the feed materials, batch size and moisture content, and vary between approximately 15 seconds to several minutes.

\subsection{Sulfur Polymer Microencapsulation}

Sulfur polymer, also known as sulfur polymer cement (SPC), is a thermoplastic material developed by the U.S. Bureau of Mines (USBM) to utilize by-product or waste sulfur generated during flue gas desulfurization and petroleum clean-up processing.[14] SPC is made by reacting elemental sulfur with a total of $5 \mathrm{wt} \%$ hydrocarbon modifiers consisting of equal parts dicyclopentadiene and oligomers of cyclopentadiene. Initially targeted for construction applications, the modified sulfur proved to be stronger than ordinary portland cement concretes and was far superior in resisting harsh chemical environments. Sulfur polymer cement was commercialized under license to USBM and currently costs about $\$ 0.12 / \mathrm{lb}$ for quantities up to one ton.[15]

Use of SPC for encapsulation of low-level radioactive, hazardous, and mixed wastes was initiated by BNL in the early 1980's and recently patented.[16] Sulfur polymer cement, with a low melting temperature $\left(119^{\circ} \mathrm{C}\right)$ and low melt viscosity $\left(\sim 25 \mathrm{cp}\right.$ at $\left.135{ }^{\circ} \mathrm{C}\right)$, is relatively easy to process and readily adaptable to microencapsulation of dry powdered wastes. Solidification is not susceptible to chemical interferences, and properties of the solidified product compare favorably with other stabilization technologies. For example, sulfur concrete compressive and tensile strengths twice those of comparable portland concretes have been achieved and full strength is reached in a matter of hours rather than weeks.[17] Sulfur concretes are highly impervious and resistant to attack in aggressive acid and salt environments.[18]

BNL work on SPC encapsulation has included encapsulation of commercial low-level radioactive waste (e.g., sodium sulfate, boric acid, and incinerator bottom ash)[19], and more recently, encapsulation of mixed waste streams. These include incinerator fly ash wastes generated at the Waste Experimental Reduction Facility (WERF) at Idaho National Engineering Laboratory (INEL)[20] and Consolidated Incinerator Facility (CIF) at the Westinghouse Savannah River Plant (SRP)[8] as well as other mixed wastes.[21] Sulfur polymer cement waste forms have demonstrated excellent performance and have easily passed 
the NRC waste form performance criteria.[22]

\subsection{EXPERIMENTAL SETUP}

Treatability work for polyethylene and sulfur polymer microencapsulation involved developing optimal polymer and waste formulations. Optimal results were based on processing considerations and leach screening tests performed at BNL. Additional waste form samples were prepared for comprehensive testing by UC. These included ten $2 \times 4$ in. right cylinders and ten 2x2x2 in. cubes for compression testing, five 1x1 in. right cylinders and ten 1x2 in. right cylinders for leach testing, and $315 \mathrm{~g}$ of pellet specimens for three replicate TCLP leach tests. Pellet specimens were cast using Teflon molds as uniform right cylinders with a maximum dimension of $9.5 \mathrm{~mm}$, as specified in the TCLP protocol. Preparation of cast TCLP pellets (rather than grinding specimens from larger monoliths) is the standard accepted practice for microencapsulated waste forms. This procedure has been used by BNL, Rocky Flats Environmental Technology Center, Envirocare of Utah, GTS Duratek (formerly SEG), Diversified Technologies, among others, and has been approved by the State of Utah, Dept. of Environmental Quality, Division of Solid and Hazardous Waste for licensing polyethylene microencapsulation.

\subsection{Silo 1 Surrogate Waste}

Fernald Silo 1 surrogate containing RCRA metals was received at BNL on September 29, 1997. Net weight on the shipping container was labeled as $66.8 \mathrm{lbs}(30.4 \mathrm{~kg})$. The surrogate was a reddish sludge cake with free-standing liquid on the surface. Some liquid had leaked from the interior 5 gallon drum into the vermiculite packing material within the overpack. Prior to sampling, the separated solid and liquid fractions were thoroughly mixed and homogenized. The moisture content was determined to be $31.2 \mathrm{wt} \%$ using a Sartorius Moisture Analyzer at $130{ }^{\circ} \mathrm{C}$ and averaged $30.9 \mathrm{wt} \%$ when measured during two replicate oven drying tests at $110^{\circ} \mathrm{C}$. A sample of the supernatent solution was removed and filtered through a 0.45 micron filter. The yellow colored filtrate was analyzed by Inductively Coupled Plasma (ICP) Spectroscopy and showed an elevated chromium level of 77.9 ppm.

\subsubsection{Polyethylene Microencapsulation of Silo 1 Surrogate Waste}

Polyethylene microencapsulation processing of as-received Silo 1 surrogate was accomplished using kinetic mixing. Preliminary processing was conducted with the nonRCRA surrogate using a laboratory-scale Lex 10 kinetic mixer rated at $45 \mathrm{~kg} / \mathrm{hr}$ (100 lbs/hr). This testing was performed as part of a sub-contract at an EcoLEX facility in Brampton, Ontario. EcoLEX and BNL paired in a Cooperative Research and Development Agreement (CRADA) for the development of kinetic mixing for polyethylene microencapsulation. Testing with the non-RCRA surrogate was conducted at waste loadings of 30,50 and $60 \mathrm{wt} \%$. Lowdensity polyethylene with a melt index of $12 \mathrm{~g} / 10 \mathrm{~min}$ was used. Batch size was maintained at a constant 400 grams (0.9 lbs). Cycle times were less than $15 \mathrm{sec}$ for all batches. The total 
number of replicates were 5 at $30 \mathrm{wt} \%, 18$ at $50 \mathrm{wt} \%$ and 9 at 60 wt\% surrogate. Product specimens including $2 \times 4 s$ and $2 \times 2 \times 2 s$ were formulated from the product at 50 and 60 wt $\%$ waste loadings. Processing results were successful despite a small, non-quantified, amount of unencapsulated material discharged with each batch. With the use of a low-density polyethylene with a higher melt index, future processing with the Silo 1 RCRA surrogate and Silo 1 actual waste was expected to be promising.

Polyethylene processing of the Silo 1 RCRA surrogate was performed at BNL with a Lex 100 rated at $450 \mathrm{~kg} / \mathrm{hr}(1000 \mathrm{lb} / \mathrm{hr})$. Figure 3.1 shows the kinetic mixer at BNL and the surrounding containment enclosure. Batch size was a constant $2 \mathrm{~kg}$ on a dry-weight basis. A low-density polyethylene with a melt index of $22 \mathrm{~g} / 10 \mathrm{~min}$ was used. This type of polyethylene was deemed optimal for kinetic mixer processing during kinetic mixer development work at BNL in FY97. Two initial runs were performed with the non-RCRA Silo 1 surrogate containing $30 \mathrm{wt} \%$ moisture at a waste loading of $30 \mathrm{wt} \%$ to verify the processibility of this surrogate. A small percentage (1-2\% of water weight) of an additive to temporarily sorb "free" water and prevent leakage from the mixing chamber was added while processing. Although kinetic mixers can process wastes with elevated moisture contents, leakage may occur around the discharge gate. This is because kinetic mixers were adapted from the plastics processing industry for waste encapsulation and were not initially designed for liquid retention and processing materials with elevated moisture contents. The function of adding a small percentage of water sorbing additive is to bind all "free" water until it can be volatilized by frictional energy, generated during a batch cycle. Processing results were successful and no liquid leakage occurred with these batches. 


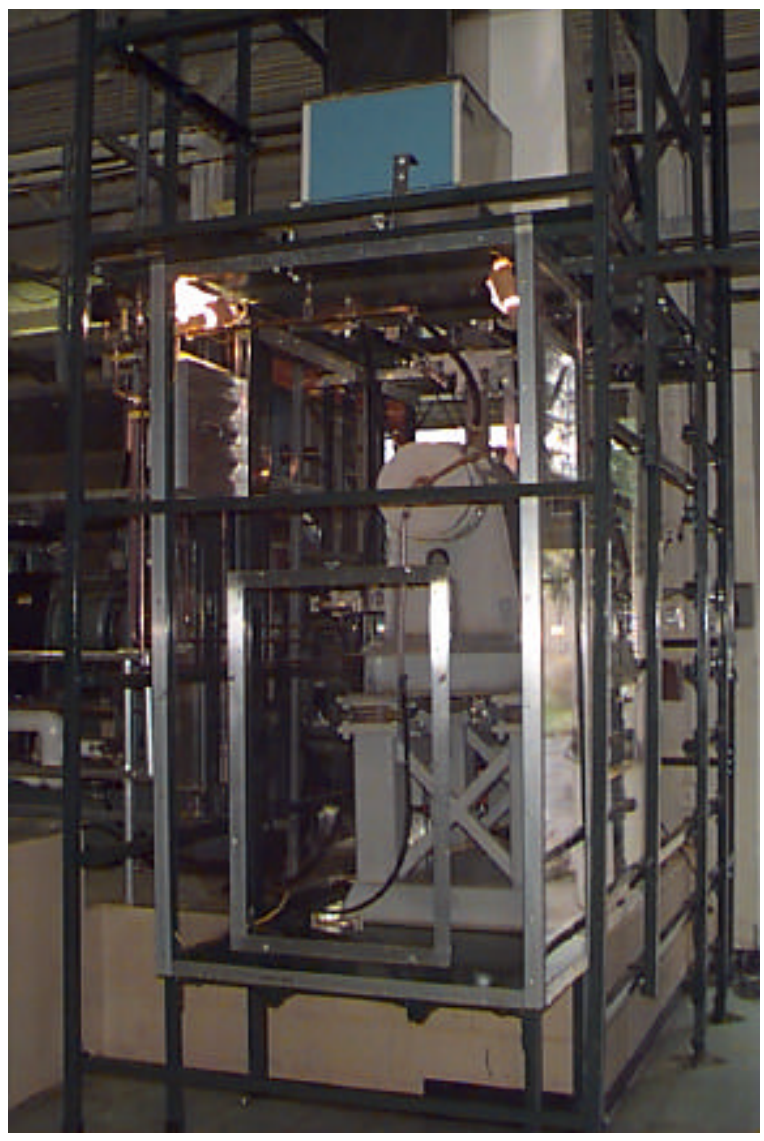

Figure 3.1. Photograph of Lex 100 Kinetic Mixer at BNL and Containment Enclosure. 3.1.2 SPC Microencapsulation of Silo 1 Surrogate Waste

To demonstrate a single vessel process for waste drying and SPC encapsulation and to determine viscosity limitations for encapsulating Silo 1 waste, a heated, double planetary (Ross) mixer was used. Operated under heat and vacuum, this mixer (Figure 3.2) can process up to 2 gallon batches. The lid/motor assembly is hinged, allowing for convenient addition or removal of material without disassembly of the blades. Additionally, two 3 in. view ports are available for inspection of batch contents or charging other materials. A 1 in. ball valve at the base of the vessel is available to discharge liquid contents.

Approximately half $(9.2 \mathrm{~kg})$ of the as-received Silo 1 RCRA surrogate was processed as three separate $3 \mathrm{~kg}$ batches. A total net weight of $6.4 \mathrm{~kg}$ of dry powder was retrieved from the three batches, yielding an apparent moisture content of $30.5 \%$. A roughing pump pulling over 30 in $\mathrm{Hg}$ vacuum was used to pull vapor from the mixer, with off-gases trapped using three water-cooled glass condensers. Surrogate batches were processed at 60 to $65^{\circ} \mathrm{C}$ and $30^{\prime \prime}$ (Hg) vacuum yielding a total of $2.4 \mathrm{~kg}$ of condensate. Under these conditions, batches took between 3.5 and 4.5 hours to reach total dryness. 


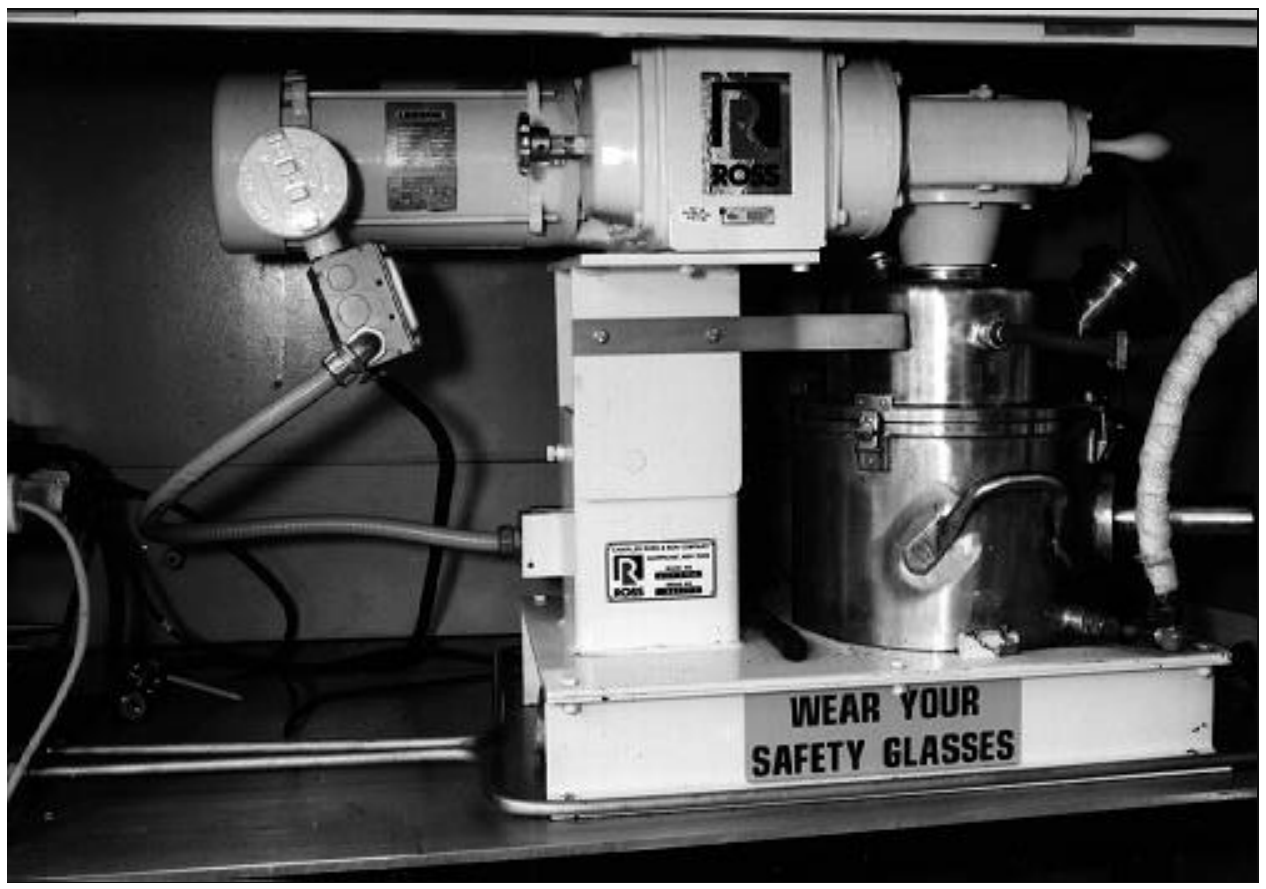

Figure 3.2. Ross Double Planetary Mixer used to dry waste and process large SPC batches.

Two thousand grams of SPC was added to a dryer batch containing nominally $2000 \mathrm{~g}$ dry (non-RCRA) surrogate, representing a waste loading of approximately $50 \mathrm{wt} \%$. When melted and mixed at $130^{\circ} \mathrm{C}$, appearance of this mixture was judged to be too viscous for optimal processing. Waste loading was reduced by adding more SPC, decreasing the waste loading to $45 \mathrm{wt} \%$. Viscosity of the mixture at this waste loading allowed for homogeneous mixing of the waste and binder. Several $2 \times 4$ in. cylindrical waste forms were prepared for density confirmation. Waste form sample densities from these initial tests were measured to be $1.86 \pm 0.01 \mathrm{~g} / \mathrm{cm}^{3}$.

Due to the limited amount of Silo 1 RCRA surrogate available, SPC formulation tests were prepared in small (200g) batches using a small lab stirrer and $150 \mathrm{ml}$ beaker (Figure 3.3). Samples were used to gauge viscosity and processibility of the formulation and to prepare samples for subsequent TCLP testing. In each case, the desired weight of SPC was first melted in a beaker at $135^{\circ} \mathrm{C}$. Dry waste (and additive, if required) were added to the molten binder, the mixture stirred for 2 minutes at approximately $500 \mathrm{rpm}$, and the material cast into pellets using Teflon molds.

After the "optimum" formulation was determined based on TCLP screening tests at BNL, two larger batches, the first $7 \mathrm{~kg}$ and the second $4 \mathrm{~kg}$, were mixed to prepare bulk samples of this composition for mechanical (compressive strength) testing and leach and immersion testing. A six liter, resistance heated stirred mixer was used to melt and 
homogenize the SPC/waste mixture (Figure 3.4). As with the smaller batches, SPC was first melted at $135 \pm 5^{\circ} \mathrm{C}$, dry surrogate and additive added, and the mixture stirred for 5 minutes. The mixture was then poured into PVC tubes or steel bar molds to form samples of the appropriate cross section dimensions. After cooling to room temperature, samples were cut to appropriate lengths using a diamond wet saw, and mass and geometric density of the resultant forms measured. Approximately 600 grams of the mixture was poured into a secondary container. This sample was remelted at a later time, remixed using the small lab stirrer and poured into Teflon ${ }^{\circledR}$ pellet forms to prepare a representative TCLP sample for the "optimized" formulation.

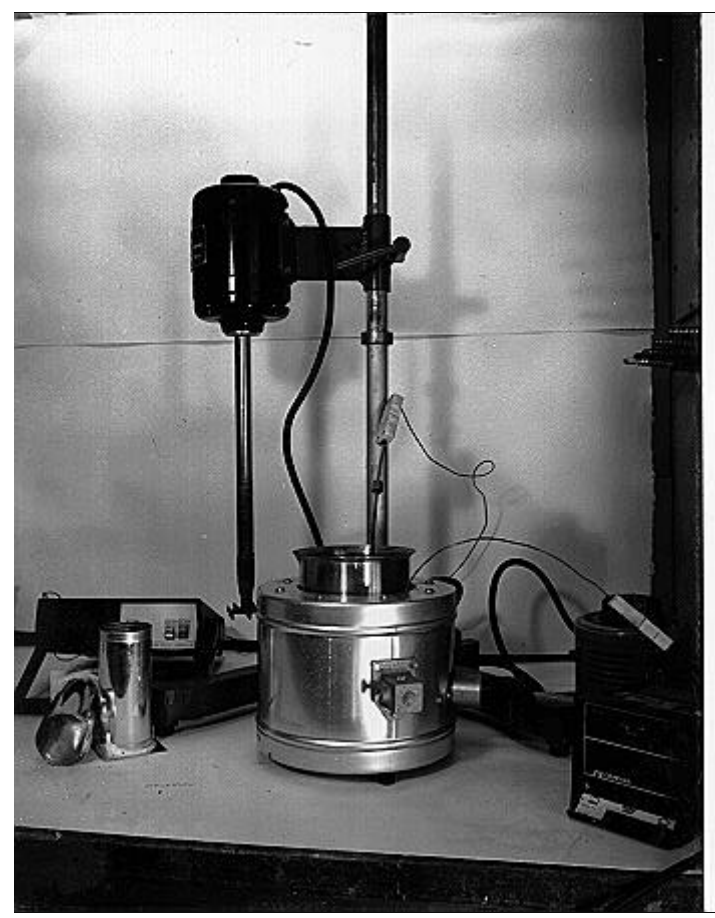

Figure 3.3. Small-batch SPC process equipment. 


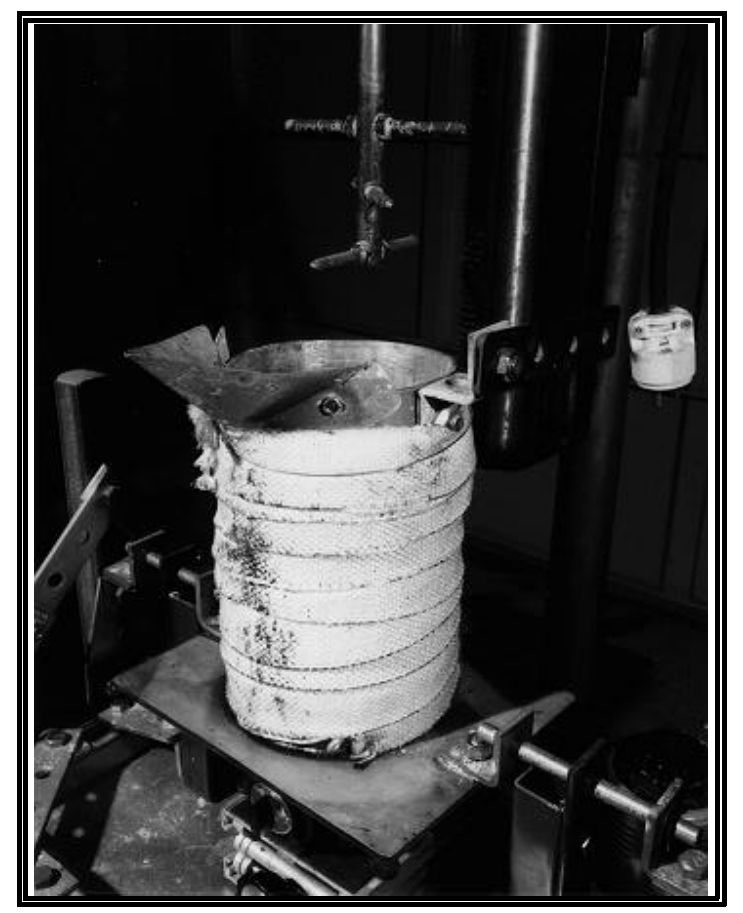

Figure 3.4. Large-batch SPC process equipment. 


\subsection{Silo 1 Actual Waste}

Silo 1 actual waste was received at BNL from Fernald on October 31, 1997 in two 30-gallon metal drums. The external surfaces of each of the 30-gal drums were smeared and no contamination was detected. The drums were surveyed with an Eberline Ion Chamber, Model RO-2 survey meter. Readings of $20 \mathrm{mR} / \mathrm{hr}$ (Drum W156899 containing $5.43 \mathrm{~kg}$ of waste) and $30 \mathrm{mR} / \mathrm{hr}$ (Drum W156897 containing $12.73 \mathrm{~kg}$ of waste) beta/gamma on contact were measured. The shipment was placed in storage for six days.

The cover of one of the 30-gallon drums containing the Silo 1 waste (W156897) was removed and smeared on November 6, 1997. No detectable contamination was observed. A layer of packing material (vermiculite) was removed to expose the top of the secondary containment, an 8-gallon metal drum. The vermiculite was transferred to a plastic bag and segregated until further evaluation could be performed. The 8-gallon drum was then lifted up (to loosen the side packing material) and placed on the top of the remaining vermiculite in the 30-gallon drum. The external surface of the smaller drum was smeared and no detectable contamination was present. A $50 \mathrm{mR} / \mathrm{hr}$ reading on contact was measured.

The 8-gallon drum was transferred to a plastic bag and transported to a HEPA fumehood. The lid of the drum was removed and the vermiculite packing material was removed until the top of a 5-gallon plastic container was exposed. The 5-gallon pail, covered with plastic shrink-wrap, was slowly lifted out of the metal drum and placed in a tray. A smear of the plastic wrap (top and sides) indicated 30,000 disintegrations per minute (dpm) beta/gamma surface contamination. At this stage, the inspection was terminated in order to further evaluate the cause of the contamination outside of the sealed drum. Based on information discussed during the Nov. 6, 1998 conference call and further discussions with BNL radiation protection personnel, the contamination was attributed to radon daughter products. The lid of the second 30-gallon drum was removed, but placed back on the drum following the results obtained for drum \#1. Both drums were then stored in a radiation storage area.

The vermiculite used to pack the 8-gallon steel drum in the 30-gallon steel drum was surveyed by radiation protection personnel using an Eberline TCM2 (Tool Contamination Monitor) which indicated levels above free release criteria $\left(>5000 \mathrm{dpm} / 100 \mathrm{~cm}^{2}\right)$. When re-checked on Nov. 10, however, radon and daughter products had decayed to levels permitting free release.

Silo 1 actual waste appeared greyish in color. It had a damp ash-like consistency, but unlike the Silo 1 surrogate, it contained no free-standing water. The moisture content of asreceived Silo 1 actual waste was calculated by oven drying overnight at $110{ }^{\circ} \mathrm{C}$. Results indicated an average moisture content of $15.5 \mathrm{wt} \%$ for Drum W156897 based on three replicates and $26.5 \mathrm{wt} \%$ for Drum W156899 based on two replicates. 
Radiological safety issues associated with Silo 1 waste (e.g., dose rates, radon emissions) led to the decision to conduct both polyethylene and SPC processing within a walk-in HEPA ventilated laboratory enclosure with additional radon source reduction ventilation.

\subsubsection{Polyethylene Microencapsulation of Silo 1 Actual Waste}

Polyethylene microencapsulation of Silo 1 actual waste was performed by extrusion using an available bench-scale extruder within a ventilated laboratory enclosure rather than kinetic mixing. The extruder was a Killion 1.25 in. diameter, non-vented single-screw extruder with an output capacity of approximately $16 \mathrm{~kg} / \mathrm{hr}(35 \mathrm{lb} / \mathrm{hr})$. A photograph of the extruder is shown in Figure 3.5. To facilitate extrusion processing, Silo 1 actual waste was oven-dried overnight at $110^{\circ} \mathrm{C}$. The polyethylene used for encapsulation processing was low-density (LDPE) with a melt index of $50 \mathrm{~g} / 10 \mathrm{~min}$. This is an injection molding grade polyethylene that was selected for extrusion-based microencapsulation during previous BNL process development studies. Continuous metering of the feed materials to the extruder was accomplished through the use of a volumetric feeder for the polyethylene and a loss-in-weight feeder for the Silo 1 waste. The extruder is equipped with four screw heating zones and one die zone that were set at $300,310,320,330$ and $310^{\circ} \mathrm{F}$, respectively. The dried Silo 1 actual waste was processed with polyethylene at a constant waste loading of $50 \mathrm{wt} \%$. No additives were included.

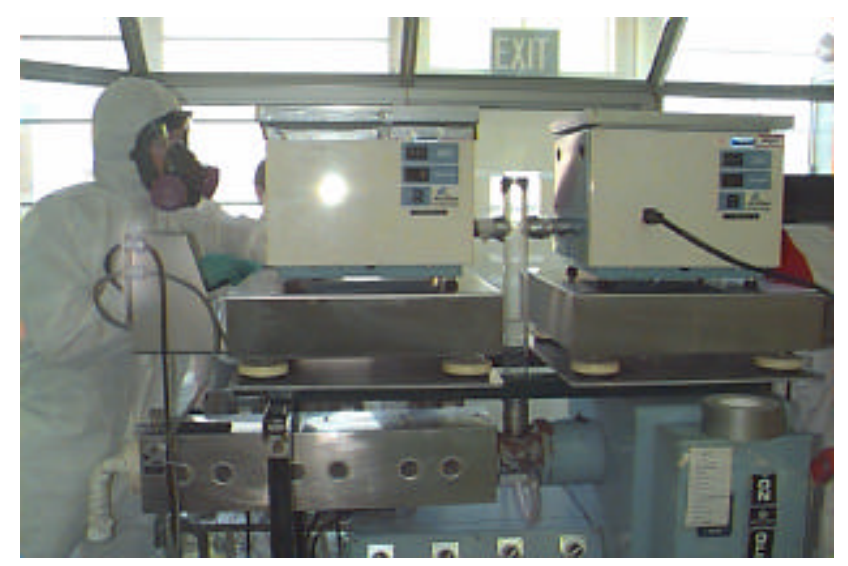

Figure 3.5. Photograph of Extruder and Feeders Used to Process Silo 1 Actual Waste.

\subsubsection{SPC Encapsulation of Silo 1 Actual Waste}

For all actual Silo waste samples, evaporative drying of the wastes was conducted by oven drying batches of the as-received waste in glass trays at $110^{\circ} \mathrm{C}$, slightly below the process temperature for SPC encapsulation. Waste batches were dried for a minimum of 12 hours. Silo 1 actual waste formed clumps on drying. The bottom of a glass beaker was used to manually crush and size reduce these clumps of material. The agglomerated Silo 1 waste was 
friable and clumps readily broke apart. Although the low viscosity of the molten SPC is amenable to virtually any particle distribution, a powder waste is preferred to ensure a homogeneous product.

Formulation optimization was not conducted for Silo 1 actual waste. Bulk samples were processed using the optimum formulation determined in surrogate testing. Samples were prepared by mixing two large (6000-7000 gram) batches using the procedure and equipment described in 3.1.2.

\subsection{Silo 3 Actual Waste}

Silo 3 actual waste was received at BNL on 12/4/97 in two drums; total shipping weight was 176 lbs. The waste was packaged in two 5 gallon buckets within steel drum overpacks. The container net weights were 21.7 lbs for container 1 (Fernald composite sample \# 97-15111) and 23.4 lbs for container 2 (Fernald composite sample \# 97-1511-2). Upon removal of the inner containers, evidence of the buildup of radon daughters was noted so the drums were left in a HEPA ventilated hood to allow for decay of the daughters. The dose rate of the waste was measured at approximately $0.5 \mathrm{mrem} / \mathrm{hr}$ on contact. The waste was observed to be a free flowing powder. The average moisture content for two replicate measurements was 3.85 wt \% following oven drying overnight at $110^{\circ} \mathrm{C}$.

\subsubsection{Polyethylene Microencapsulation of Silo 3 Actual Waste}

Polyethylene microencapsulation and formulation testing for Silo 3 actual waste was performed at BNL with the Lex 100 kinetic mixer. Since a surrogate was not available for this waste, formulation development was conducted with the actual waste. Batch size was a constant $2 \mathrm{~kg}$ on a dry-weight basis and low-density polyethylene with a melt index of $22 \mathrm{~g} / 10$ min was used. Batches were processed at three waste loadings, 40, 50 and $60 \mathrm{wt} \%$, with and with the inclusion of additives. The effect of sulfide additive was tested at each waste loading and at $60 \mathrm{wt} \%$ a second additive was used to minimize dispersion and improve waste particle "wetting."

\subsubsection{SPC Microencapsulation of Silo 3 Actual Waste}

As with Silo 1 surrogate, formulation testing was conducted for Silo 3 actual waste to determine optimum waste loading based on processibility of the dry waste and leachability of the encapsulated product. Formulation test samples were made as 200 gram batches using a lab oven to melt the polymer at $135^{\circ} \mathrm{C}$, and a small lab stirrer to homogenize the waste into the molten SPC. The encapsulated product was cast as pellets for subsequent TCLP testing. Batch viscosity was used to gauge processibility of the mixture.

Following determination of an "optimum" formulation, two larger batches were prepared using the six liter, resistance heated stirred mixer to melt and homogenize the 
$\mathrm{SPC} /$ waste mixture. As before, $\mathrm{SPC}$ was first melted at $135 \pm 5^{\circ} \mathrm{C}$ prior to addition of dry surrogate and additive. The molten mixture was stirred for 5 minutes then poured into PVC tubes or steel bar molds to form samples of the appropriate cross section dimensions. After cooling to room temperature, samples were cut to appropriate lengths using a diamond wet saw, and mass and geometric density of the resultant forms measured. Approximately 400 grams of pellets were prepared as representative TCLP sample for the "optimized" formulation.

\subsection{EXPERIMENTAL RESULTS}

The Toxicity Characteristic Leaching Procedure (TCLP) was used to gauge leach performance of polyethylene and sulfur polymer microencapsulated Silo wastes, and to establish baseline leach performance of unencapsulated Silo wastes. TCLP is an 18 hour extraction of $100 \mathrm{~g}$ of sample in $2000 \mathrm{~g}$ of a buffered leachant (either $\mathrm{pH} 2.88 \pm 0.05 \mathrm{or}$ $4.93 \pm 0.05)$. To determine the appropriate extraction fluid, a pretest was conducted for each material using a $5 \mathrm{~g}$ representative sample. In each case, $96.5 \mathrm{ml}$ of deionized water was added to the $5 \mathrm{~g}$ sample, and the mixture agitated for 5 minutes. If $\mathrm{pH}$ of this solution is less than $\mathbf{5 . 0}$, then the $4.93 \mathrm{pH}$ extract is to be used. If pretest $\mathrm{pH}$ is $>5.0,3.5 \mathrm{ml}$ of $1.0 \mathrm{~N} \mathrm{HCl}$ is added to the solution and the mixture is heated to $50^{\circ} \mathrm{C}$ for 10 minutes, then cooled to room temperature. If final $\mathrm{pH}$ of this solution is $<5.0$, then the $4.93 \mathrm{pH}$ extract is to be used; if $\mathrm{pH}>5.0$, then the pH 2.88 extract is indicated. Following TCLP extraction, the leachate is filtered through a 0.4 - 0.6 micron glass fiber filter, then analyzed for RCRA metals present. In this case, a Varian Liberty 100 ICP was used for all analyses. RCRA metal standards, with concentrations between 0.1 and $10 \mathrm{mg} / \mathrm{l}$, were prepared fresh daily using a SPEX multi-element stock solution.

\subsection{Silo 1 Surrogate Waste}

Untreated Silo 1 surrogate had a significant buffering capacity and required use of TCLP extraction fluid \#2 with a pH of 2.88. All LDPE and SPC encapsulated Silo 1 surrogate waste forms required extraction fluid \#1 ( $\mathrm{pH} \mathrm{4.93).} \mathrm{All} \mathrm{leachates} \mathrm{from} \mathrm{materials} \mathrm{containing}$ Silo 1 surrogate were analyzed for $\mathrm{Pb}, \mathrm{Ba}, \mathrm{Cr}$, As, and Se. For the baseline/untreated Silo 1 surrogate, all metals were below their maximum allowable concentrations with the exception of $\mathrm{Pb}$, with a concentration of $156 \mathrm{mg} / \mathrm{l}$. This concentration is well above the TCLP limit of $5 \mathrm{mg} / \mathrm{l}$ and the Universal Treatment Standard (UTS) limit of $0.75 \mathrm{mg} / \mathrm{l}$. Results of the thermoplastic encapsulated materials are given in Sections 4.1.1 and 4.1.2.

\subsubsection{Polyethylene Microencapsulation of Silo 1 Surrogate Waste}

During processibility testing with the Silo 1 RCRA surrogate a number of process parameters were varied including the waste loading, the surrogate moisture content, the use of a small percentage of sorption additive, and the use of an additive to reduce toxic metal 
solubility and improve leach performance of final waste forms. The surrogate was processed either with no moisture (dried) or $30 \mathrm{wt} \%$ moisture. A summary of the processibility tests is shown in Table 4.1. Leach testing was performed in accordance with the TCLP for each of the surrogate compositions. Inductively Coupled Plasma (ICP) Spectroscopy was used to analyze leachate solutions for $\mathrm{Pb}, \mathrm{Ba}, \mathrm{Cr}$, As and $\mathrm{Se}$. A summary of leach results for Silo 1 surrogate is shown in Table 4.2 with the TCLP and the more stringent Universal Treatment Standard (UTS) concentration limits.

Table 4.1. Summary of LDPE Microencapsulation Kinetic Mixer Processibility Testing with Silo 1 RCRA Surrogate.

\begin{tabular}{|c|c|c|c|c|}
\hline \multirow[t]{2}{*}{ Batch } & \multicolumn{2}{|c|}{ Surrogate } & \multirow[t]{2}{*}{ Additives } & \multirow[t]{2}{*}{ Cycle Time } \\
\hline & Loading & $\%$ Moisture & & \\
\hline F1 & $30 \mathrm{wt} \%$ & $30 \mathrm{wt} \%$ & $\begin{array}{l}2 w^{2} \% \mathrm{SA}^{(\mathrm{a})} \\
2.5 \mathrm{wt} \% \mathrm{Na}_{2} \mathrm{~S}\left(\mathrm{Na}_{2} \mathrm{~S}-9 \mathrm{H}_{2} \mathrm{O}\right)\end{array}$ & $2 \min 9 \mathrm{sec}$ \\
\hline F2 & 30 wt $\%$ & $30 \mathrm{wt} \%$ & $1 \mathrm{wt} \% \mathrm{SA}$ & $1 \mathrm{~min} 28 \mathrm{sec}$ \\
\hline F3 & $50 \mathrm{wt} \%$ & dry & none & $50 \mathrm{sec}$ \\
\hline $\mathbf{F 4}$ & $50 \mathrm{wt} \%$ & dry & $2.5 \mathrm{wt} \% \mathrm{Na}_{2} \mathrm{~S}$ (dried) & $20.3 \mathrm{sec}$ \\
\hline F5 & 50 wt \% & dry & $3.5 \mathrm{wt} \% \mathrm{Na}_{2} \mathrm{~S}$ (dried) & $21.3 \mathrm{sec}$ \\
\hline F6 & 50 wt \% & 30 wt $\%$ & $3.5 \mathrm{wt} \% \mathrm{Na}_{2} \mathrm{~S}$ (dried) & $1 \mathrm{~min} 11 \mathrm{sec}$ \\
\hline F7A & 50 wt \% & 30 wt $\%$ & $\begin{array}{l}1 \mathrm{wt} \% \mathrm{SA} \\
3.5 \mathrm{wt} \% \mathrm{Na}_{2} \mathrm{~S} \text { (dried) }\end{array}$ & $4 \mathrm{~min} 25 \mathrm{sec}$ \\
\hline F7B & $50 \mathrm{wt} \%$ & $30 \mathrm{wt} \%$ & $\begin{array}{l}2 \mathrm{wt} \% \mathrm{SA} \\
3.5 \mathrm{wt} \% \mathrm{Na}_{2} \mathrm{~S} \text { (dried) }\end{array}$ & $2 \mathrm{~min} 38 \mathrm{sec}$ \\
\hline F8 & 50 wt $\%$ & $30 \mathrm{wt} \%$ & $\begin{array}{l}2 \mathrm{wt} \% \mathrm{SA} \\
7.5 \mathrm{wt} \% \mathrm{Na}_{2} \mathrm{~S} \text { (dried) }\end{array}$ & $>8$ min \\
\hline
\end{tabular}

(a) SA: sorption additive 
Table 4.2. LDPE Microencapsulation Kinetic Mixer TCLP Leach Results (mg/l) for Silo1 Surrogate.

\begin{tabular}{|c|c|c|c|c|c|}
\hline Composition & As & $\mathbf{B a}$ & $\mathbf{C r}$ & $\mathbf{P b}$ & Se \\
\hline TCLP limit & 5.0 & 100 & 5.0 & 5.0 & 1.0 \\
\hline UTS limit & 5.0 & 21 & 0.85 & 0.75 & 5.7 \\
\hline Silo 1 surrogate (untreated/baseline) & nd $^{(\mathbf{a})}$ & 0.5719 & nd & 156 & nd \\
\hline F1; $30 w t \%, 30$ wt $\%$ moisture, $2.5 \% \mathrm{Na}_{2} \mathrm{~S}$ (wet) & 0.1012 & 3.455 & 0.0276 & 1.571 & nd \\
\hline F2; 30wt $\%, 30$ wt $\%$ moisture, no additive & 0.0771 & 0.6965 & 0.0114 & 1.322 & nd \\
\hline F3; 50wt \%, no moisture, no additive & nd & 0.5489 & 0.0121 & 2.543 & nd \\
\hline F4; 50wt $\%$, no moisture, 2.5 wt $\% \mathrm{Na}_{2} \mathrm{~S}$ (dry) & 0.0928 & 1.143 & $\mathbf{0 . 0 2 5 3}$ & 0.7122 & nd \\
\hline F5; 50wt \%, no moisture, 3.5 wt $\% \mathrm{Na}_{2} \mathrm{~S}$ (dry) & nd & 0.8809 & 0.0295 & nd & nd \\
\hline F6; 50wt $\%, 30 \%$ moisture, 3.5 wt $\% \mathrm{Na}_{2} \mathrm{~S}$ (dry) & nd & 0.4653 & 0.0157 & 3.063 & 0.1493 \\
\hline F8; 50wt \%, 30\% moisture, $7.5 \mathrm{wt} \% \mathrm{Na}_{2} \mathrm{~S}$ (dry) & nd & 1.473 & $\mathbf{0 . 0 2 0 7}$ & 1.204 & nd \\
\hline
\end{tabular}

(a) nd: below detection limits for ICP; As 0.012, Ba 0.00007, Cr 0.004, Pb 0.014, Se 0.037

The rationale for progressively changing the batch compositions during processibility testing was based on qualitative processing observations and leach testing results. The first polyethylene microencapsulation trials were conducted at a conservative waste loading of 30 wt $\%$ and a $30 \mathrm{wt} \%$ surrogate moisture content to be representative of the actual waste. These batches (F1 and F2) were successfully processed, i.e., resulted in homogeneously distributed microencapsulated product. Batch $\mathrm{F} 1$, with $2.5 \%$ metal binding additive $\left(\mathrm{Na}_{2} \mathrm{~S}-9 \mathrm{H}_{2} \mathrm{O}\right)$, required a longer cycle time probably due to the hydrated form of the sulfide additive. The product from this batch had a rubbery consistency and a vulcanized appearance. This was not observed for the comparable batch (F2) without sodium sulfide additive. The TCLP leachate concentrations from batches $\mathrm{F} 1$ and $\mathrm{F} 2$ were dramatically less than the untreated surrogate baseline for $\mathrm{Pb}$ and below the TCLP metal concentration limits. In fact, all Silo 1 surrogate compositions were below TCLP limits for metals of concern in this surrogate. Ba, $\mathrm{Cr}$, As and Se were also below the more stringent UTS limits in all Silo 1 surrogate compositions. However, for batches F1 and F2, the Pb concentrations exceeded the UTS limit of $0.75 \mathrm{mg} / \mathrm{l}$. No beneficial impact resulted from the inclusion of sulfide additive in batch F1 compared to batch F2 which had a similar composition.

To evaluate the effect of surrogate moisture content on processing and to investigate any potential impact on waste form performance, testing was conducted using dry surrogate and a $50 \mathrm{wt} \%$ surrogate loading. Based on previous experience processing dry materials, this waste loading should be readily achievable from both a processing and waste form 
performance standpoint. Batches (F3, F4, and F5) were processed containing $0 \%, 2.5 \%$ and 3.5\% sulfide additive. For these batches, as well as all subsequent batches, the sodium sulfide was dried to remove the waters of hydration and crushed to a fine powder. Processing results were successful. Cycle times were short and easily discernable. Both batches containing sodium sulfide (F4 at $2.5 \mathrm{wt} \%$ and $\mathrm{F} 5$ at $3.5 \mathrm{wt} \%$ ) resulted in TCLP leachate concentrations below UTS limits for all metals including $\mathrm{Pb}$. Based on the success of these batch compositions, additional processing was performed at a waste loading of $50 \mathrm{wt} \%$ with wet surrogate containing $30 \mathrm{wt} \%$ moisture. Dried sodium sulfide was added at $3.5 \mathrm{wt} \%$ (Batch F6) and 7.5 wt\% (Batch F8). TCLP results for these batches indicated $\mathrm{Pb}$ leachate concentrations below the TCLP limit but above the UTS limit. The batch containing $7.5 \mathrm{wt} \% \mathrm{Na}_{2} \mathrm{~S}$ had lower leachability than with $3.5 \mathrm{wt} \%$ sulfide additive, but both had greater leaching than batches processed with dry surrogate.

Processibility testing with the Silo 1 surrogate determined that the kinetic mixer was capable of processing the wet surrogate, but waste forms formulated from batches processed with wet surrogate had poorer leach results than batches processed with dry surrogate. Compositions with $50 \mathrm{wt} \%$ surrogate and no moisture performed better than a lower waste loading (30 wt \%) with $30 \mathrm{wt} \%$ moisture. The effect of surrogate moisture content on waste form leaching is believed to be attributable to a reaction with the $\mathrm{Na}_{2} \mathrm{~S}$ additive during batch blending. Since kinetic mixing is a batch process, the feed materials are measured and mixed together prior to processing. The $\mathrm{Na}_{2} \mathrm{~S}$ may be reacting and forming metal sulfides with other metals in the surrogate. For example, iron compounds in the surrogate such as iron oxide $\left(\mathrm{Fe}_{2} \mathrm{O}_{3}\right)$ may react to form $\mathrm{FeS}$. The reduction of $\mathrm{Fe}$ (III) to $\mathrm{Fe}$ (II) would consume $\mathrm{Na}_{2} \mathrm{~S}$ and explain a color difference observed between processing with and without moisture in the surrogate. The as-received surrogate had a reddish color. All batch compositions containing $30 \mathrm{wt} \%$ moisture turned black upon the addition of $\mathrm{Na}_{2} \mathrm{~S}$ during blending. Fe (III), such as $\mathrm{Fe}_{2} \mathrm{O}_{3}$, has a red color whereas Fe (II), such as FeS, has a black color. During dry blending (premixing batches of dry surrogate), no color change was noted, probably because there was insufficient molecular contact for any reactions to occur.

Optimal results were obtained by processing dry surrogate at a waste loading of $50 \mathrm{wt} \%$ with $3.5 \mathrm{wt} \% \mathrm{Na}_{2} \mathrm{~S}$; leachate concentrations of all metals were well below UTS limits. The use of $2.5 \mathrm{wt} \% \mathrm{Na}_{2} \mathrm{~S}$ additive at this composition instead of $3.5 \%$ also produced metal leachate concentrations below UTS limits.

Low-density polyethylene and Silo 1 surrogate waste form specimens were formulated during processibility testing for shipment to FDF and future performance testing by the University of Cincinnati. Leach specimens, including TCLP pellets, nominal 1x1 in. and 1x2 in. cylinders, were formulated from a composition of $50 \mathrm{wt} \%$ dry surrogate, $46.5 \mathrm{wt} \% \mathrm{LDPE}$ and $3.5 \mathrm{wt} \% \mathrm{Na}_{2} \mathrm{~S}$. Nominal $2 \times 2 \times 2$ in. cubes were formulated from the non-RCRA Silo 1 surrogate at a composition of $50 \mathrm{wt} \%$ dry surrogate and $50 \mathrm{wt} \%$ LDPE. Nominal $2 \times 4$ in. cylinders also contained $50 \mathrm{wt} \%$ surrogate, $46.5 \mathrm{wt} \%$ LDPE and $3.5 \mathrm{wt} \% \mathrm{Na}_{2} \mathrm{~S}$, but were prepared from surrogate originally containing 30 wt\% moisture. A photograph of 
polyethylene and Silo 1 surrogate waste form specimens shipped to FDF is shown in Figure 4.1.

Dimensions and calculated waste form densities for each sample are summarized in Tables 4.3 - 4.6. The calculated densities vary slightly between a low of $1.28 \mathrm{~g} / \mathrm{cm}^{3}$ for $2 \times 2 \times 2$ cubes to $1.44 \mathrm{~g} / \mathrm{cm}^{3}$ for $1 \times 2$ right cylinders. The variation in density among sample types is a function of the sample molding method for which slightly different compressive forces were used and/or slight differences in the waste/polymer ratios. The small deviation and percent error between replicates for each sample type indicate excellent product homogeneity.

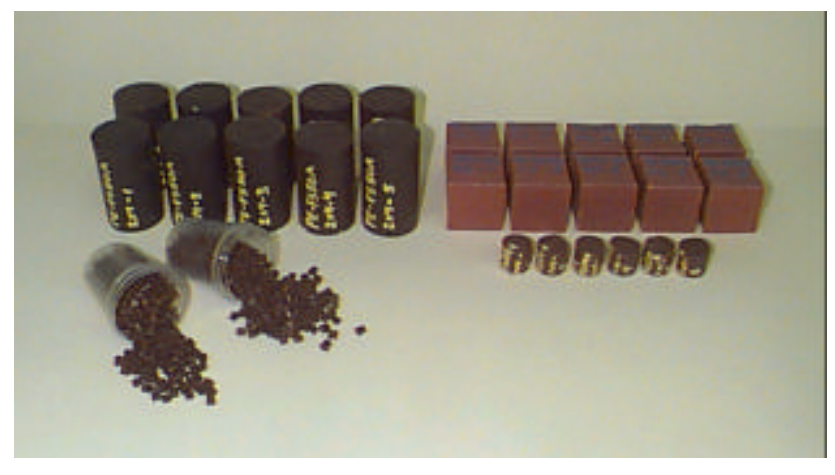

Figure 4.1. LDPE and Silo 1 Surrogate Waste Form Specimens Prepared for FDF.

Table 4.3. LDPE Microencapsulated Silo 1 Surrogate 2x4 in. Cylindrical Specimens.

\begin{tabular}{|c|c|c|c|c|c||}
\hline Sample & $\begin{array}{c}\text { Weight } \\
(\mathrm{g})\end{array}$ & $\begin{array}{c}\text { Height } \\
(\mathrm{cm})\end{array}$ & $\begin{array}{c}\text { Diameter } \\
(\mathrm{cm})\end{array}$ & $\begin{array}{c}\text { Volume } \\
\left(\mathrm{cm}^{3}\right)\end{array}$ & $\begin{array}{c}\text { Density } \\
\left(\mathrm{g} / \mathrm{cm}^{3}\right)\end{array}$ \\
\hline \hline 1 & 267.07 & 9.04 & 5.23 & 194.44 & 1.37 \\
\hline 2 & 265.28 & 9.04 & 5.21 & 192.55 & 1.38 \\
\hline 3 & 263.33 & 9.22 & 5.16 & 192.53 & 1.37 \\
\hline 4 & 252.83 & 8.84 & 5.16 & 184.57 & 1.37 \\
\hline 5 & 264.97 & 9.09 & 5.18 & 191.75 & 1.38 \\
\hline 6 & 269.34 & 9.02 & 5.21 & 192.01 & 1.40 \\
\hline 7 & 256.66 & 9.04 & 5.16 & 188.81 & 1.36 \\
\hline 8 & 249.35 & 8.66 & 5.18 & 182.64 & 1.37 \\
\hline 9 & 261.05 & 8.92 & 5.23 & 191.70 & 1.36 \\
\hline 10 & 263.64 & 8.79 & 5.26 & 190.81 & 1.38 \\
\hline
\end{tabular}


0.63

Table 4.4. LDPE Microencapsulated Silo 1 Surrogate 1x1 in. Cylindrical Specimens.

\begin{tabular}{||c|c|c|c|c|c||}
\hline \hline Sample & $\begin{array}{c}\text { Weight } \\
(\mathrm{g})\end{array}$ & $\begin{array}{c}\text { Height } \\
(\mathrm{cm})\end{array}$ & $\begin{array}{c}\text { Diameter } \\
(\mathrm{cm})\end{array}$ & $\begin{array}{c}\text { Volume } \\
\left(\mathrm{cm}^{3}\right)\end{array}$ & $\begin{array}{c}\text { Density } \\
\left(\mathrm{g} / \mathrm{cm}^{3}\right)\end{array}$ \\
\hline \hline 1 & 17.79 & 2.51 & 2.54 & 12.74 & 1.40 \\
\hline 2 & 18.20 & 2.54 & 2.54 & 12.87 & 1.41 \\
\hline 3 & 18.40 & 2.57 & 2.57 & 13.26 & 1.39 \\
\hline 4 & 18.25 & 2.62 & 2.57 & 13.52 & 1.35 \\
\hline 5 & 17.98 & 2.54 & 2.54 & 12.87 & 1.40 \\
\hline & & & & & $\begin{array}{r}\text { Mean } \\
\text { Std. Dev. }\end{array}$ \\
\hline
\end{tabular}

Table 4.5. LDPE Microencapsulated Silo 1 Surrogate 1x2 in. Cylindrical Specimens.

\begin{tabular}{|c|c|c|c|c|c|}
\hline Sample & $\begin{array}{c}\text { Weight } \\
\text { (g) }\end{array}$ & $\begin{array}{c}\text { Height } \\
(\mathrm{cm})\end{array}$ & $\begin{array}{c}\text { Diameter } \\
(\mathbf{c m})\end{array}$ & $\begin{array}{c}\text { Volume } \\
\left(\mathrm{cm}^{3}\right)\end{array}$ & $\begin{array}{l}\text { Density } \\
\left(\mathrm{g} / \mathrm{cm}^{3}\right) \\
\end{array}$ \\
\hline 1 & 38.09 & 5.16 & 2.54 & 26.19 & 1.45 \\
\hline 2 & 38.39 & 5.16 & 2.56 & 26.53 & 1.45 \\
\hline 3 & 38.21 & 5.18 & 2.54 & 26.32 & 1.45 \\
\hline 4 & 38.01 & 5.16 & 2.55 & 26.36 & 1.44 \\
\hline 5 & 38.24 & 5.16 & 2.57 & 26.65 & 1.43 \\
\hline 6 & 38.35 & 5.17 & 2.56 & 26.63 & 1.44 \\
\hline 7 & 37.60 & 5.14 & 2.54 & 26.11 & 1.44 \\
\hline 8 & 38.24 & 5.17 & 2.56 & 26.60 & 1.44 \\
\hline 9 & 38.50 & 5.17 & 2.56 & 26.57 & 1.45 \\
\hline \multirow[t]{2}{*}{10} & 38.40 & 5.18 & 2.55 & 26.41 & 1.45 \\
\hline & & & & $\begin{array}{r}\text { Mean } \\
\text { Std. Dev. } \\
20 \text { 作 }\end{array}$ & $\begin{array}{c}1.44 \\
0.007 \\
0.005 \\
\end{array}$ \\
\hline
\end{tabular}


\begin{tabular}{|ll||} 
& \\
\hline & Error $\quad 0.33$ \\
\hline
\end{tabular}

Table 4.6. LDPE Microencapsulated Silo 1 Surrogate 2x2x2 in. Cubic Specimens.

\begin{tabular}{||c|c|c|c|c|c|c||}
\hline \hline Sample & $\begin{array}{c}\text { Weight } \\
(\mathrm{g})\end{array}$ & $\begin{array}{c}\text { Side A } \\
(\mathrm{cm})\end{array}$ & $\begin{array}{c}\text { Side B } \\
(\mathrm{cm})\end{array}$ & $\begin{array}{c}\text { Side C } \\
(\mathrm{cm})\end{array}$ & $\begin{array}{c}\text { Volume } \\
\left(\mathrm{cm}^{3}\right)\end{array}$ & $\begin{array}{c}\text { Density } \\
\left(\mathrm{g} / \mathrm{cm}^{3}\right)\end{array}$ \\
\hline \hline 1 & 152.8 & 5.18 & 4.93 & 4.93 & 125.82 & 1.21 \\
\hline 2 & 164.3 & 5.16 & 4.93 & 4.95 & 125.84 & 1.31 \\
\hline 3 & 162.94 & 5.16 & 4.90 & 4.93 & 124.55 & 1.31 \\
\hline 4 & 165.86 & 5.13 & 4.93 & 4.93 & 124.58 & 1.33 \\
\hline 5 & 161.66 & 5.18 & 4.93 & 4.95 & 126.46 & 1.28 \\
\hline 6 & 160.24 & 5.18 & 4.90 & 4.90 & 124.52 & 1.29 \\
\hline 7 & 162.04 & 5.13 & 4.93 & 4.93 & 124.58 & 1.30 \\
\hline 8 & 159.28 & 5.16 & 4.90 & 4.93 & 124.55 & 1.28 \\
\hline 9 & 159.05 & 5.16 & 4.93 & 4.93 & 125.20 & 1.27 \\
\hline 10 & 156.34 & 5.18 & 4.90 & 4.93 & 125.17 & 1.25 \\
\hline
\end{tabular}

\subsubsection{SPC Microencapsulation of Silo 1 Surrogate Waste}

Silo 1 surrogate waste processing with sulfur polymer cement (SPC) was conducted in $200 \mathrm{~g}$ batches. SPC encapsulations were initiated at $30 \mathrm{wt} \%$ dry surrogate (70 wt\% SPC), as per the treatability test plan. Formulations with 40, 50, and $60 \mathrm{wt} \%$ dry surrogate were also prepared. Approximately $120 \mathrm{~g}$ of pellets were made from each batch for subsequent TCLP testing. Waste loadings higher than $60 \mathrm{wt} \%$ may be processible from a viscosity standpoint, but were not prepared in that high lead concentrations in the surrogate made acceptable TCLP performance unlikely.

Because of the high concentrations of toxic metals present in the Silo 1 surrogate waste, SPC samples were also made containing dry, powdered $\mathrm{Na}_{2} \mathrm{~S}$, an additive intended to bind soluble RCRA metals and enhance TCLP performance. Batches containing a total of 2.1, 2.8, 3.5, and $4.2 \mathrm{wt} \%$ of sulfide additive (7\% of dry surrogate weight) were prepared for $30,40,50$, and $60 \mathrm{wt} \%$ waste loadings, respectively. Mass of SPC was reduced commensurately in each batch. In addition, batches of $30 \mathrm{wt} \%$ surrogate were prepared with 3 and $4.5 \mathrm{wt} \%$ sulfide 
additive, and batches of $50 \mathrm{wt} \%$ surrogate were prepared with 5 and $7.5 \mathrm{wt} \%$ sulfide additive (10 and $15 \%$ of dry surrogate weight).

TCLP testing was conducted accordance with EPA protocol, with leachates analyzed by ICP. Pretests of all SPC encapsulated Silo surrogate samples indicated use of the 4.93 \pm 0.05 pH extract. Concentrations of As, Se, Ba, and $\mathrm{Cr}$ were all below current TCLP and UTS limits. Lead concentrations of SPC encapsulated materials, shown in Table 4.7, all showed marked improvement compared to the unencapsulated waste. Several formulations resulted in currently acceptable $\mathrm{Pb}$ concentrations ( $<5 \mathrm{ppm})$, but none passed the more stringent UTS level $(<0.75$ ppm).

Table 4.7. TCLP Lead Concentrations (mg/l) for SPC/Silo 1 Surrogate Test Formulations.

\begin{tabular}{|l|c|c|c|c||}
\hline Wt\% Silo 1 Surrogate & No Additive & $7 \%^{(\mathrm{a})}$ Additive & $10 \%^{(\mathrm{a})}$ Additive & $15 \%^{(\mathrm{a})}$ Additive \\
\hline \hline $\begin{array}{l}\text { Silo 1 Surrogate } \\
\text { (untreated/baseline) }\end{array}$ & 156.0 & $\mathbf{n} / \mathbf{a}^{[\mathrm{b}]}$ & $\mathrm{n} / \mathbf{a}$ & $\mathrm{n} / \mathrm{a}$ \\
\hline 30 & 13.0 & $16.3^{(\mathrm{c})}$ & 3.3 & 2.2 \\
\hline 40 & 30.5 & 9.5 & $\mathrm{n} / \mathrm{a}$ & $\mathrm{n} / \mathrm{a}$ \\
\hline 50 & 36.2 & 11.4 & 11.8 & 5.3 \\
\hline 60 & 39.6 & 4.1 & $\mathrm{n} / \mathrm{a}$ & $\mathrm{n} / \mathrm{a}$ \\
\hline
\end{tabular}

(a) as percent of dry surrogate weight in formulation (total wt \% of additive varied with waste loading).

[b] not measured

(c) this sample contained $5 \%$ additive.

An "optimized" sulfur polymer cement (SPC) formulation was chosen based on the TCLP matrix shown above. This formulation consisted of $40 \mathrm{wt} \%$ Silo 1 surrogate, $54 \mathrm{wt} \%$ SPC, and $6 \mathrm{wt} \% \mathrm{Na}_{2} \mathrm{~S}$ additive (15\% of Silo 1 surrogate weight), intended to react with and precipitate soluble heavy metals as they leach from the waste form. While none of the SPC encapsulated Silo 1 samples were below UTS limits for lead leachability, samples containing 50 wt \% Silo 1 surrogate and $15 \mathrm{wt} \% \mathrm{Na}_{2} \mathrm{~S}$ defined the apparent maximum waste loading to pass current TCLP limits. A Silo 1 surrogate loading of $40 \mathrm{wt} \%$ was chosen to provide a margin of safety.

Two large batches, the first $7 \mathrm{~kg}$ and the second $4 \mathrm{~kg}$, were made to prepare all surrogate waste form test samples required for UC waste form performance testing. Two 30" long cylinders were cast in 2" ID Schedule 40 PVC tubing. Another 30" long cylinder was cast in 1" ID PVC tubing. Three 2"x2"x12" prisms were similarly cast in steel molds. Finally, approximately $1 \mathrm{~kg}$ of material was poured into a Teflon® beaker. This material was used to 
subsequently cast approximately $500 \mathrm{~g}$ of TCLP pellet specimens with a maximum dimension of $9.5 \mathrm{~mm}$, as specified in the protocol for TCLP testing.

Silo 1 surrogate waste form test specimens were shipped to FDF on 12/12/97. A total of 37 SPC specimens were included. SPC and Silo 1 surrogate waste forms prepared for shipment to FDF are shown in Figure 4.2. Two replicate batches of pellets (105 $\mathrm{g}$ each) were provided for TCLP testing. Sample size and density data are given in Tables 4.8 - 4.11. The mean weighted density of Silo 1 surrogate waste forms was $2.12 \mathrm{~g} / \mathrm{cm}^{3}$.

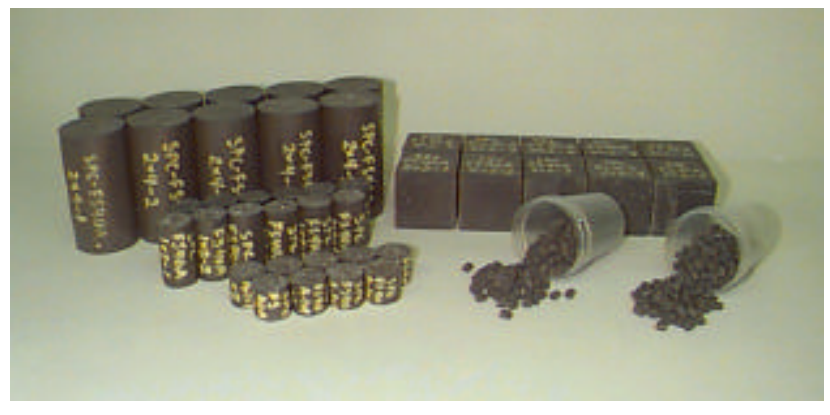

Figure 4.2. SPC and Silo 1 Surrogate Waste Form Specimens Prepared for FDF.

Table 4.8. SPC Microencapsulated Silo 1 Surrogate 2x4 in. Cylindrical Specimens.

\begin{tabular}{|c|c|c|c|c|c|}
\hline Sample & $\begin{array}{c}\text { Weight } \\
\text { (g) }\end{array}$ & $\begin{array}{c}\text { Height } \\
(\mathrm{cm})\end{array}$ & $\begin{array}{c}\text { Diameter } \\
(\mathbf{c m})\end{array}$ & $\begin{array}{c}\text { Volume } \\
\left(\mathrm{cm}^{3}\right)\end{array}$ & $\begin{array}{r}\text { Density } \\
\left(\mathrm{g} / \mathrm{cm}^{3}\right) \\
\end{array}$ \\
\hline 1 & 467.75 & 10.08 & 5.22 & 215.57 & 2.17 \\
\hline 2 & 466.44 & 10.12 & 5.23 & 217.12 & 2.15 \\
\hline 3 & 467.24 & 10.12 & 5.22 & 216.49 & 2.16 \\
\hline 4 & 464.88 & 10.16 & 5.22 & 217.30 & 2.14 \\
\hline 5 & 463.37 & 10.25 & 5.22 & 219.20 & 2.11 \\
\hline 6 & 472.51 & 10.12 & 5.25 & 219.13 & 2.16 \\
\hline 7 & 466.34 & 10.12 & 5.26 & 220.08 & 2.12 \\
\hline 8 & 468.19 & 10.15 & 5.25 & 219.36 & 2.13 \\
\hline 9 & 461.59 & 10.12 & 5.25 & 219.34 & 2.10 \\
\hline 10 & 453.37 & 10.16 & 5.24 & 219.32 & 2.07 \\
\hline & & & & $\begin{array}{r}\text { Mean } \\
\text { Std. Dev. } \\
2 o ́ \\
\text { \% Error }\end{array}$ & $\begin{array}{c}2.13 \\
0.029 \\
0.021 \\
0.98\end{array}$ \\
\hline
\end{tabular}


Table 4.9. SPC Microencapsulated Silo 1 Surrogate $1 x 1$ in. Cylindrical Specimens.

\begin{tabular}{|c|c|c|c|c|c|}
\hline Sample & $\begin{array}{c}\text { Weight } \\
\text { (g) }\end{array}$ & $\begin{array}{l}\text { Height } \\
\text { (cm) }\end{array}$ & $\begin{array}{c}\text { Diameter } \\
\text { (cm) }\end{array}$ & $\begin{array}{c}\text { Volume } \\
\left(\mathrm{cm}^{3}\right)\end{array}$ & $\begin{array}{l}\text { Density } \\
\left(\mathrm{g} / \mathrm{cm}^{3}\right)\end{array}$ \\
\hline 2 & 28.10 & 2.48 & 2.63 & 13.40 & 2.10 \\
\hline 3 & 27.75 & 2.44 & 2.63 & 13.30 & 2.09 \\
\hline 4 & 27.79 & 2.43 & 2.63 & 13.23 & 2.10 \\
\hline 5 & 27.98 & 2.45 & 2.63 & 13.29 & 2.11 \\
\hline \multirow[t]{5}{*}{6} & 27.40 & 2.43 & 2.64 & 13.27 & 2.06 \\
\hline & & & & Mean & 2.09 \\
\hline & & & & Std. Dev. & 0.014 \\
\hline & & & & $20 ́$ & 0.018 \\
\hline & & & & & 0.86 \\
\hline
\end{tabular}

Table 4.10. SPC Microencapsulated Silo 1 Surrogate 1x2 in. Cylindrical Specimens.

\begin{tabular}{|c|c|c|c|c|c|}
\hline Sample & $\begin{array}{c}\text { Weight } \\
\text { (g) }\end{array}$ & $\begin{array}{c}\text { Height } \\
\text { (cm) }\end{array}$ & $\begin{array}{c}\text { Diameter } \\
(\mathbf{c m})\end{array}$ & $\begin{array}{c}\text { Volume } \\
\left(\mathrm{cm}^{3}\right)\end{array}$ & $\begin{array}{l}\text { Density } \\
\left(\mathrm{g} / \mathrm{cm}^{3}\right)\end{array}$ \\
\hline 1 & 57.23 & 5.03 & 2.64 & 27.46 & 2.08 \\
\hline 2 & 57.76 & 5.04 & 2.65 & 27.75 & 2.08 \\
\hline 3 & 56.92 & 5.01 & 2.63 & 27.25 & 2.09 \\
\hline 4 & 57.94 & 5.12 & 2.64 & 27.92 & 2.08 \\
\hline 5 & 57.70 & 5.10 & 2.64 & 27.95 & 2.06 \\
\hline 6 & 57.76 & 5.12 & 2.64 & 28.04 & 2.06 \\
\hline 7 & 54.54 & 5.10 & 2.62 & 27.40 & 1.99 \\
\hline 8 & 54.59 & 5.11 & 2.62 & 27.50 & 1.99 \\
\hline 9 & 54.34 & 5.07 & 2.61 & 27.20 & 2.00 \\
\hline \multirow[t]{5}{*}{10} & 54.60 & 5.09 & 2.62 & 27.35 & 2.00 \\
\hline & & & & Mean & 2.04 \\
\hline & & & & Std. Dev. & 0.042 \\
\hline & & & & & 0.030 \\
\hline & & & & \% Error & 1.46 \\
\hline
\end{tabular}


Table 4.11. SPC Microencapsulated Silo 1 Surrogate 2x2x2 in. Cubic Specimens.

\begin{tabular}{|c|c|c|c|c|c|c|}
\hline Sample & $\begin{array}{c}\text { Weight } \\
\text { (g) }\end{array}$ & $\begin{array}{c}\text { Side A } \\
\text { (cm) }\end{array}$ & $\begin{array}{c}\text { Side B } \\
(\mathbf{c m})\end{array}$ & $\begin{array}{c}\text { Side C } \\
(\mathbf{c m})\end{array}$ & $\begin{array}{c}\text { Volume } \\
\left(\mathrm{cm}^{3}\right)\end{array}$ & $\begin{array}{l}\text { Density } \\
\left(\mathrm{g} / \mathrm{cm}^{3}\right)\end{array}$ \\
\hline 1 & 279.47 & 5.03 & 5.09 & 5.07 & 129.78 & 2.15 \\
\hline 2 & 284.54 & 5.18 & 5.09 & 5.08 & 133.98 & 2.12 \\
\hline 3 & 279.25 & 5.16 & 5.08 & 5.09 & 133.26 & 2.10 \\
\hline 4 & 274.10 & 5.16 & 5.08 & 5.09 & 133.26 & 2.06 \\
\hline 5 & 287.65 & 5.16 & 5.07 & 5.07 & 132.60 & 2.17 \\
\hline 6 & 282.24 & 5.15 & 5.07 & 5.09 & 132.80 & 2.13 \\
\hline 7 & 279.90 & 5.14 & 5.07 & 5.08 & 132.54 & 2.11 \\
\hline 8 & 277.53 & 5.18 & 5.08 & 5.08 & 133.65 & 2.08 \\
\hline 9 & 283.16 & 5.19 & 5.09 & 5.09 & 134.45 & 2.11 \\
\hline \multirow[t]{5}{*}{10} & 278.93 & 5.21 & 5.08 & 5.10 & 135.11 & 2.06 \\
\hline & & & & & Mear & 2.11 \\
\hline & & & & & Std. Dev & 0.035 \\
\hline & & & & & 20 & 0.025 \\
\hline & & & & & \% Erro & 1.18 \\
\hline
\end{tabular}

\subsection{Silo 1 Actual Waste}

TCLP testing of neither the untreated nor the thermoplastic encapsulated Silo 1 actual waste was done at BNL due to the activity contained in the Silo 1 waste. TCLP samples of both unencapsulated and microencapsulated materials were prepared and sent to UC, however, as described below.

\subsubsection{Polyethylene Microencapsulation of Silo 1 Actual Waste}

Extrusion processing of the Silo 1 actual waste was successful. A photograph of extrusion processing while preparing $2 \times 4$ in. waste form specimens is shown in Figure 4.3. A total of $6.88 \mathrm{~kg}(15.2 \mathrm{lb})$ of waste was processed over two extrusion trials. Product specimens were formulated from the extrudate (extruder product) including TCLP pellets, nominal 1x1 in. right cylinders, $1 \times 2$ in. right cylinders, $2 \times 4$ in. right cylinders and $2 \times 2 \times 2$ in. cubes. Product quantities included over 300 grams of TCLP pellets for three replicate TCLP tests, (5) replicate $1 \times 1$ in. cylinders and (10) replicates for $1 \times 2$ in. cylinders, $2 \times 4$ in. cylinders and 2x2x2 in. cubes. A photograph of the polyethylene and Silo 1 actual waste samples prepared for FDF are shown 
in Figure 4.4.

Dimensions and calculated waste form densities for each sample are summarized in Tables 4.12 - 4.15. The calculated densities vary slightly between a low of $1.27 \mathrm{~g} / \mathrm{cm}^{3}$ for $2 \times 2 \times 2$ in. cubes to $1.36 \mathrm{~g} / \mathrm{cm}^{3}$ for $1 \times 2$ in. right cylinders. A similar trend was noted with the Silo 1 surrogate waste forms. The variation in density between different sample types is a function of the sample molding method for which slightly different compressive forces were used. For the Silo 1 surrogate as well as the actual waste, the lowest densities were measured for the $2 \times 2 \times 2$ in. cubes and the highest for the $1 \times 2$ in. cylinders. This consistency demonstrates the dependence of the product density on the molding method. Small deviations and percent errors between replicates for each sample type, as noted with the surrogate, indicate excellent product homogeneity.

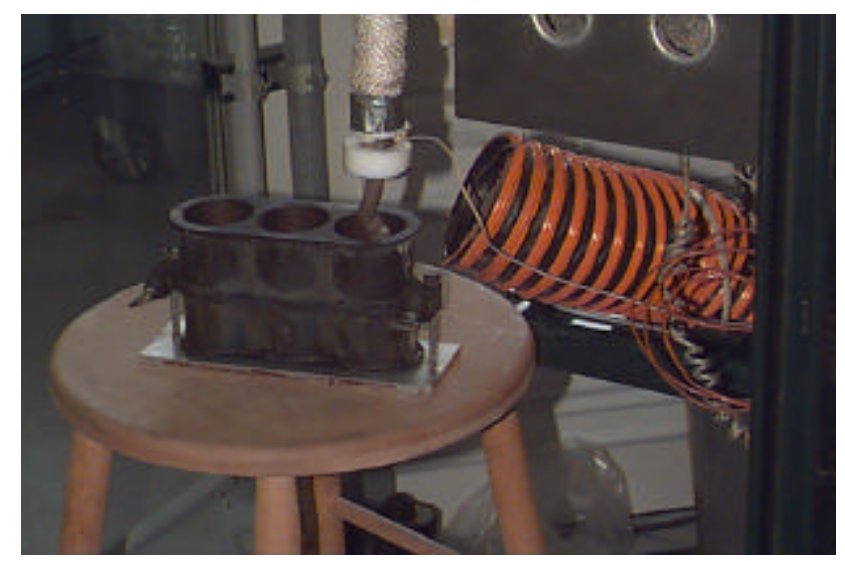

Figure 4.3. Extrusion Processing of Silo 1 Actual Waste During Fabrication of 2x4 in. Waste Form Specimens.

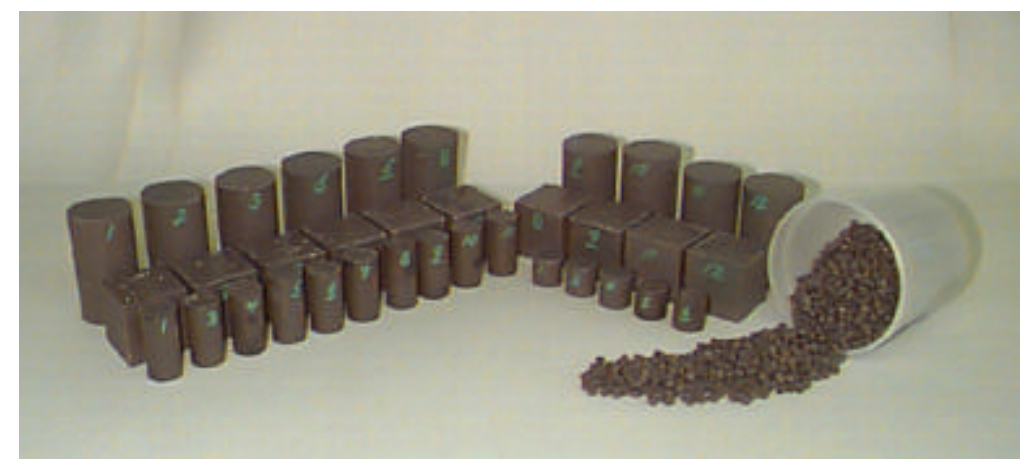

Figure 4.4. LDPE and Silo 1 Actual Waste Form Specimens Prepared for FDF. 
Table 4.12. LDPE Encapsulated Silo 1 Waste $2 \times 4$ in. Cylindrical Specimens.

\begin{tabular}{|c|c|c|c|c|c|}
\hline Sample & $\begin{array}{c}\text { Weight } \\
\text { (g) }\end{array}$ & $\begin{array}{c}\text { Height } \\
(\mathrm{cm})\end{array}$ & $\begin{array}{c}\text { Diameter } \\
(\mathbf{c m})\end{array}$ & $\begin{array}{c}\text { Volume } \\
\left(\mathrm{cm}^{3}\right)\end{array}$ & $\begin{array}{l}\text { Density } \\
\left(\mathrm{g} / \mathbf{c m}^{3}\right)\end{array}$ \\
\hline 1 & 230.69 & 8.97 & 4.98 & 174.72 & 1.32 \\
\hline 2 & 237.98 & 9.07 & 5.07 & 183.11 & 1.30 \\
\hline 3 & 236.86 & 9.08 & 5.00 & 178.29 & 1.33 \\
\hline 4 & 237.01 & 9.08 & 5.04 & 181.15 & 1.31 \\
\hline 5 & 237.48 & 9.18 & 4.99 & 179.53 & 1.32 \\
\hline 6 & 235.94 & 9.04 & 5.01 & 178.21 & 1.32 \\
\hline 7 & 217.30 & 8.53 & 4.98 & 166.15 & 1.31 \\
\hline 8 & 232.40 & 9.05 & 5.02 & 179.12 & 1.30 \\
\hline 9 & 218.80 & 8.50 & 4.98 & 165.56 & 1.32 \\
\hline \multirow[t]{2}{*}{10} & 220.49 & 8.53 & 5.01 & 168.16 & 1.31 \\
\hline & & & & $\begin{array}{r}\text { Mean } \\
\text { Std. Dev. } \\
20 ́ \\
\text { \% Error }\end{array}$ & $\begin{array}{c}1.31 \\
0.009 \\
0.007 \\
0.50\end{array}$ \\
\hline
\end{tabular}

Table 4.13. LDPE Encapsulated Silo 1 Waste $1 \times 1$ in. Cylindrical Specimens.

\begin{tabular}{||c|c|c|c|c|c||}
\hline \hline Sample & $\begin{array}{c}\text { Weight } \\
(\mathrm{g})\end{array}$ & $\begin{array}{c}\text { Height } \\
(\mathrm{cm})\end{array}$ & $\begin{array}{c}\text { Diameter } \\
(\mathrm{cm})\end{array}$ & $\begin{array}{c}\text { Volume } \\
\left(\mathrm{cm}^{3}\right)\end{array}$ & $\begin{array}{c}\text { Density } \\
\left(\mathrm{g} / \mathrm{cm}^{3}\right)\end{array}$ \\
\hline \hline 1 & 15.63 & 2.37 & 2.56 & 12.20 & 1.28 \\
\hline 2 & 16.41 & 2.50 & 2.54 & 12.67 & 1.30 \\
\hline 3 & 17.78 & 2.73 & 2.54 & 13.83 & 1.29 \\
\hline 4 & 17.27 & 2.46 & 2.58 & 12.86 & 1.34 \\
\hline 5 & 17.46 & 2.52 & 2.58 & 13.17 & 1.33 \\
\hline & & & & & $\begin{array}{r}\text { Mean } \\
\text { Std. Dev. }\end{array}$ \\
\hline
\end{tabular}


Table 4.14. LDPE Encapsulated Silo 1 Waste 1x2 in. Cylindrical Specimens.

\begin{tabular}{|c|c|c|c|c|c|}
\hline Sample & $\begin{array}{c}\text { Weight } \\
\text { (g) }\end{array}$ & $\begin{array}{c}\text { Height } \\
\text { (cm) }\end{array}$ & $\begin{array}{c}\text { Diameter } \\
(\mathbf{c m})\end{array}$ & $\begin{array}{c}\text { Volume } \\
\left(\mathrm{cm}^{3}\right)\end{array}$ & $\begin{array}{l}\text { Density } \\
\left(\mathrm{g} / \mathrm{cm}^{3}\right)\end{array}$ \\
\hline 1 & 36.58 & 5.21 & 2.56 & 26.71 & 1.37 \\
\hline 2 & 33.70 & 4.93 & 2.56 & 25.28 & 1.33 \\
\hline 3 & 34.54 & 5.00 & 2.54 & 25.31 & 1.36 \\
\hline 4 & 37.35 & 5.30 & 2.56 & 27.17 & 1.37 \\
\hline 5 & 33.90 & 5.00 & 2.56 & 25.63 & 1.32 \\
\hline 6 & 36.72 & 5.16 & 2.56 & 26.43 & 1.39 \\
\hline 7 & 36.94 & 5.25 & 2.55 & 26.71 & 1.38 \\
\hline 8 & 34.02 & 4.94 & 2.55 & 25.13 & 1.35 \\
\hline 9 & 35.21 & 5.00 & 2.55 & 25.44 & 1.38 \\
\hline \multirow[t]{5}{*}{10} & 35.48 & 5.03 & 2.56 & 25.89 & 1.37 \\
\hline & & & & Mean & 1.36 \\
\hline & & & & Std. Dev. & 0.021 \\
\hline & & & & $20 ́$ & 0.015 \\
\hline & & & & $\%$ Error & 1.12 \\
\hline
\end{tabular}


Table 4.15. LDPE Encapsulated Silo 1 Waste 2x2x2 in. Cubic Specimens.

\begin{tabular}{||c|c|c|c|c|c|c||}
\hline Sample & $\begin{array}{c}\text { Weight } \\
(\mathrm{g})\end{array}$ & $\begin{array}{c}\text { Side A } \\
(\mathrm{cm})\end{array}$ & $\begin{array}{c}\text { Side B } \\
(\mathrm{cm})\end{array}$ & $\begin{array}{c}\text { Side C } \\
(\mathrm{cm})\end{array}$ & $\begin{array}{c}\text { Volume } \\
\left(\mathrm{cm}^{3}\right)\end{array}$ & $\begin{array}{c}\text { Density } \\
\left(\mathrm{g} / \mathrm{cm}^{3}\right)\end{array}$ \\
\hline \hline 1 & 162.30 & 5.02 & 5.00 & 5.04 & 126.50 & 1.28 \\
\hline 2 & 162.96 & 5.04 & 5.04 & 5.00 & 127.01 & 1.28 \\
\hline 3 & 160.36 & 5.05 & 5.03 & 5.00 & 126.88 & 1.26 \\
\hline 4 & 160.13 & 5.01 & 5.00 & 5.11 & 128.01 & 1.25 \\
\hline 5 & 163.46 & 4.98 & 4.98 & 5.14 & 127.47 & 1.28 \\
\hline 6 & 158.99 & 5.00 & 5.02 & 5.08 & 127.51 & 1.25 \\
\hline 7 & 161.42 & 4.98 & 4.98 & 5.13 & 127.53 & 1.27 \\
\hline 8 & 159.74 & 4.98 & 4.99 & 5.12 & 127.23 & 1.26 \\
\hline 9 & 158.55 & 5.02 & 5.00 & 5.00 & 125.50 & 1.26 \\
\hline 10 & 153.78 & 4.98 & 4.95 & 4.95 & 122.02 & 1.26 \\
\hline
\end{tabular}

\subsubsection{SPC Microencapsulation of Silo 1 Actual Waste}

Formulation of SPC encapsulated Silo 1 actual waste was selected on the basis of the optimization matrix performed for Silo 1 surrogate. This "optimized" formulation was determined to contain $40 \mathrm{wt} \%$ Silo 1 waste, $54 \mathrm{wt} \%$ SPC, and $6 \mathrm{wt} \%$ additive (15\% of dry surrogate weight). As with Silo 1 surrogate, two large batches of the SPC/dry Silo 1 waste were processed in the six liter mixer to produce samples for shipment to FDF. Figure 4.5 shows a batch of SPC and Silo 1 waste being poured into a cylindrical waste form mold. The first batch was inadvertently made with 43 wt\% waste, 50.6 wt $\%$ SPC and 6.4 wt\% additive, however, as a tray containing a larger amount of waste was mistakenly added to the SPC. As there was no adverse impact on viscosity or mixability due to this error, the remaining batches were also made with $43 \mathrm{wt} \%$ waste so that the entire lot of samples would be consistent with this formulation. Types and quantities of samples prepared for shipment to FDF were the same as for Silo 1 surrogate, except that only nine $2 \times 4$ waste forms were produced. Three sets of TCLP pellets were prepared as opposed to two for surrogate waste. SPC and Silo 1 actual waste forms prepared for shipment to FDF are shown in Figure 4.6. Waste form dimensions and densities are given in Table 4.16-19. Mean density of SPC encapsulated Silo 1 actual 
waste was $2.10 \mathrm{~g} / \mathrm{cm}^{3}$.

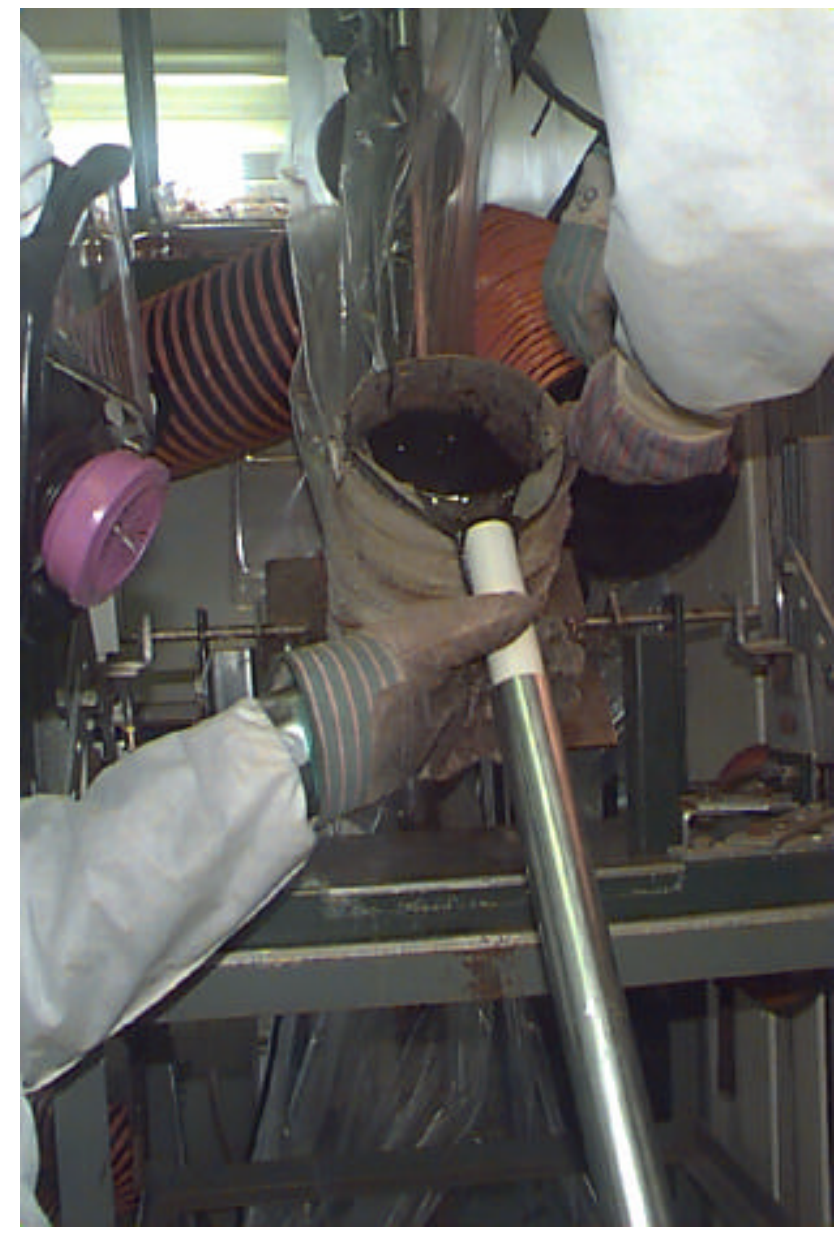

Figure 4.5. Photograph of a SPC/Silo 1 Waste Batch Being Poured Into a Cylindrical Mold.

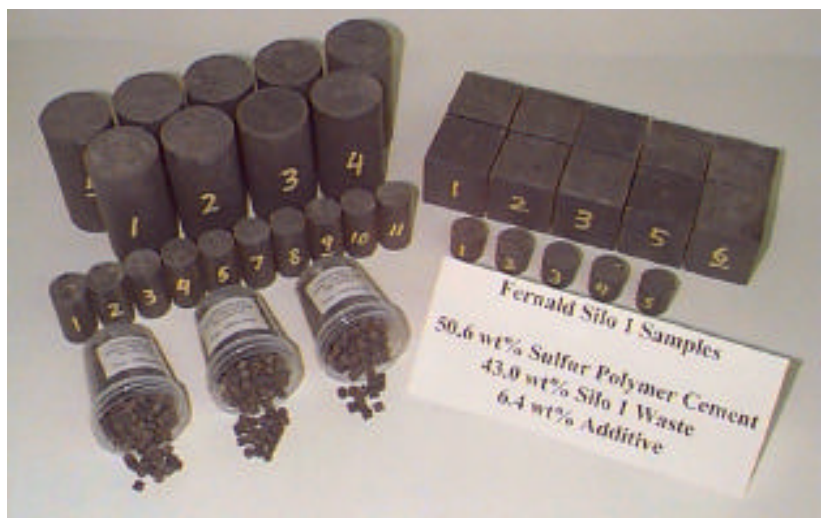


Figure 4.6. SPC and Silo 1 Actual Waste Form Specimens Prepared for FDF. Table 4.16. SPC Microencapsulated Silo 1 Waste $2 \times 4$ in. Cylindrical Specimens.

\begin{tabular}{|c|c|c|c|c|c|}
\hline Sample & $\begin{array}{c}\text { Weight } \\
\text { (g) }\end{array}$ & $\begin{array}{c}\text { Height } \\
(\mathrm{cm})\end{array}$ & $\begin{array}{c}\text { Diameter } \\
(\mathbf{c m})\end{array}$ & $\begin{array}{c}\text { Volume } \\
\left(\mathrm{cm}^{3}\right)\end{array}$ & $\begin{array}{l}\text { Density } \\
\left(\mathrm{g} / \mathrm{cm}^{3}\right)\end{array}$ \\
\hline 1 & 466.26 & 10.15 & 5.23 & 218.25 & 2.14 \\
\hline 2 & 469.69 & 10.19 & 5.24 & 219.79 & 2.14 \\
\hline 3 & 468.27 & 10.21 & 5.24 & 220.06 & 2.13 \\
\hline 4 & 462.21 & 10.11 & 5.24 & 218.42 & 2.12 \\
\hline 5 & 465.20 & 10.18 & 5.25 & 220.05 & 2.11 \\
\hline 6 & 464.64 & 10.18 & 5.24 & 219.75 & 2.11 \\
\hline 7 & 463.01 & 10.18 & 5.24 & 219.33 & 2.11 \\
\hline 8 & 462.54 & 10.18 & 5.24 & 219.45 & 2.11 \\
\hline \multirow[t]{5}{*}{9} & 461.26 & 10.18 & 5.24 & 219.60 & 2.10 \\
\hline & & & & Mean & 2.12 \\
\hline & & & & Std. Dev. & 0.012 \\
\hline & & & & & 0.009 \\
\hline & & & & \% Error & 0.43 \\
\hline
\end{tabular}

Table 4.17. SPC Microencapsulated Silo 1 Waste $1 x 1$ in. Cylindrical Specimens.

\begin{tabular}{||c|c|c|c|c|c||}
\hline \hline Sample & $\begin{array}{c}\text { Weight } \\
(\mathrm{g})\end{array}$ & $\begin{array}{c}\text { Height } \\
(\mathrm{cm})\end{array}$ & $\begin{array}{c}\text { Diameter } \\
(\mathrm{cm})\end{array}$ & $\begin{array}{c}\text { Volume } \\
\left(\mathrm{cm}^{3}\right)\end{array}$ & $\begin{array}{c}\text { Density } \\
\left(\mathrm{g} / \mathrm{cm}^{3}\right)\end{array}$ \\
\hline \hline 1 & 27.76 & 2.45 & 2.63 & 13.28 & 2.09 \\
\hline 2 & 28.36 & 2.50 & 2.63 & 13.57 & 2.09 \\
\hline 3 & 28.34 & 2.50 & 2.63 & 13.58 & 2.09 \\
\hline 4 & 28.20 & 2.50 & 2.62 & 13.51 & 2.09 \\
\hline 5 & 28.45 & 2.52 & 2.63 & 13.68 & 2.08 \\
\hline & & & & Mean & 2.09 \\
& & & & Std. Dev. & 0.004 \\
& & & & 20.005 \\
\hline
\end{tabular}


Table 4.18. SPC Microencapsulated Silo 1 Waste $1 \times 2$ in. Cylindrical Specimens.

\begin{tabular}{|c|c|c|c|c|c|}
\hline Sample & $\begin{array}{c}\text { Weight } \\
\text { (g) }\end{array}$ & $\begin{array}{c}\text { Height } \\
(\mathrm{cm})\end{array}$ & $\begin{array}{c}\text { Diameter } \\
(\mathrm{cm})\end{array}$ & $\begin{array}{c}\text { Volume } \\
\left(\mathrm{cm}^{3}\right)\end{array}$ & $\begin{array}{l}\text { Density } \\
\left(\mathrm{g} / \mathrm{cm}^{3}\right)\end{array}$ \\
\hline 1 & 58.69 & 5.06 & 2.63 & 27.41 & 2.14 \\
\hline 2 & 58.14 & 5.04 & 2.63 & 27.35 & 2.13 \\
\hline 3 & 57.44 & 5.04 & 2.63 & 27.35 & 2.10 \\
\hline 4 & $\mathbf{5 7 . 5 7}$ & 5.03 & 2.63 & 27.25 & 2.11 \\
\hline 5 & $\mathbf{5 7 . 5 2}$ & 5.04 & 2.63 & 27.29 & 2.11 \\
\hline 7 & 58.73 & 5.18 & 2.63 & 28.08 & 2.09 \\
\hline 8 & 57.69 & 5.09 & 2.63 & 27.55 & 2.09 \\
\hline 9 & $\mathbf{5 7 . 8 1}$ & 5.09 & 2.63 & 27.59 & 2.10 \\
\hline 10 & 58.12 & 5.11 & 2.63 & 27.69 & 2.10 \\
\hline \multirow[t]{5}{*}{11} & 58.32 & 5.12 & 2.63 & 27.79 & 2.10 \\
\hline & & & & Mean & 2.11 \\
\hline & & & & Std. Dev. & 0.015 \\
\hline & & & & & 0.011 \\
\hline & & & & \% Error & 0.51 \\
\hline
\end{tabular}


Table 4.19. SPC Microencapsulated Silo 1 Waste $2 \times 2 \times 2$ in. Cubic Specimens.

\begin{tabular}{|c|c|c|c|c|c|c|}
\hline Sample & $\begin{array}{c}\text { Weight } \\
\text { (g) }\end{array}$ & $\begin{array}{c}\text { Side A } \\
\text { (cm) }\end{array}$ & $\begin{array}{c}\text { Side B } \\
(\mathrm{cm})\end{array}$ & $\begin{array}{c}\text { Side C } \\
(\mathbf{c m})\end{array}$ & $\begin{array}{c}\text { Volume } \\
\left(\mathrm{cm}^{3}\right)\end{array}$ & $\begin{array}{l}\text { Density } \\
\left(\mathrm{g} / \mathrm{cm}^{3}\right)\end{array}$ \\
\hline 1 & 270.02 & 5.04 & 5.06 & 5.08 & 129.46 & 2.09 \\
\hline 2 & 269.01 & 5.16 & 5.05 & 5.08 & 132.59 & 2.03 \\
\hline 3 & 273.02 & 5.07 & 5.06 & 5.08 & 130.44 & 2.09 \\
\hline 5 & 272.82 & 5.16 & 5.10 & 5.07 & 133.26 & 2.05 \\
\hline 6 & 269.50 & 5.11 & 5.09 & 5.08 & 132.15 & 2.04 \\
\hline 7 & 272.36 & 5.08 & 5.08 & 5.08 & 131.03 & 2.08 \\
\hline 8 & 274.08 & 5.09 & 5.08 & 5.07 & 131.03 & 2.09 \\
\hline 9 & 270.02 & 5.12 & 5.09 & 5.07 & 132.01 & 2.05 \\
\hline 10 & 269.06 & 5.12 & 5.08 & 5.07 & 131.88 & 2.04 \\
\hline \multirow[t]{2}{*}{11} & 271.83 & 5.07 & 5.07 & 5.07 & 130.38 & 2.08 \\
\hline & & & & & $\begin{array}{r}\text { Mean } \\
\text { Std. Dev. } \\
2 o ́ \\
\text { \% Error }\end{array}$ & $\begin{array}{c}2.06 \\
0.024 \\
0.017 \\
0.83\end{array}$ \\
\hline
\end{tabular}

\subsection{Silo 3 Actual Waste}

Treatability investigations for polyethylene and sulfur polymer encapsulation of Silo 3 were performed using actual Silo 3 waste. A surrogate was not provided so formulation development and feasibility processing was conducted with the actual waste. Baseline TCLP tests of the unencapsulated waste were performed using $\mathrm{pH} 2.88$ extract. ICP results indicated the untreated waste exceeded both TCLP and UTS limits for Se and As (2.64 and $9.44 \mathrm{mg} / \mathrm{l}$, respectively) and the UTS limits for $\mathrm{Cd}$ and $\mathrm{Cr}(0.249$ and $3.05 \mathrm{mg} / \mathrm{l}$, respectively). Concentrations of $\mathrm{Cd}, \mathrm{Cr}, \mathrm{Pb}$, and Ba were less than current TCLP limits.

\subsubsection{Polyethylene Microencapsulation of Silo 3 Actual Waste}

Polyethylene microencapsulation processing of actual Silo 3 waste was accomplished using kinetic mixing. Batch size was maintained at a consistent $2 \mathrm{~kg}$ on a dry weight basis. The polyethylene used was low-density with a melt index of $22 \mathrm{~g} / 10 \mathrm{~min}$. During formulation development, the batch composition was varied including the waste loading, and the use of additives to improve leach performance and encapsulation effectiveness. The additives 
consisted of sodium sulfide to reduce toxic metal leachability and a proprietary binding additive to minimize dispersion and promote particle surface wetting during kinetic mixer processing. Formulations were prepared at waste loadings of 40,50 and $60 \mathrm{wt} \%$. Additives were included at the expense of polyethylene to ensure a consistent waste loading. The waste was processed in an as-received condition, i.e., containing $3.85 \mathrm{wt} \%$ moisture.

A summary of processibility testing conditions with the Silo 3 waste is shown in Table 4.20. For each batch, two waste loadings are indicated. The nominal loading refers to the waste loading in the feed batches prior to processing. The actual loading refers to the waste loading estimated to be in the encapsulated product. These values are usually equivalent. However, due to the fine particle size of Silo 3 waste, some waste was dispersed and discharged unencapsulated from the kinetic mixer. For batches F9-F13, the actual waste loading was less than the nominal loading due to dispersion and unencapsulated material. The product from batches F9-F13 was observed to have unencapsulated waste on the surface. Simple handling of the product improved the surface appearance. Batch F14 which contained a small percentage of proprietary additive to reduce dispersibility and enhance mixing, produced the optimal processing results. Product appearance was excellent and no dispersion or unencapsulated material was produced.

Process cycle times for each Silo 3 waste composition are shown in Table 4.20. The cycle time is seen to increase with increasing waste loading from 25-30 seconds for batches containing nominal $40 \mathrm{wt} \%$ Silo 3 waste to over one minute for batches containing nominal $60 \mathrm{wt} \%$ waste. This is due to the physical properties of the waste. Cycle time in the kinetic mixer is dependent on the rate of generation of frictional heat through shear and particle to particle contact. These results indicate that the Silo 3 waste is not an abrasive material since cycle times increase as the proportion of Silo 3 waste in each batch increases. The cycle times would also have been shorter had the waste been dried prior to processing. The waste in each batch contained $3.85 \mathrm{wt} \%$ moisture which was vaporized while processing.

Leach testing was performed in accordance with the TCLP for each composition. Leach results, in consideration with processing results and observations, were used to gauge the success and effectiveness of each formulation. A summary of leach results for the untreated waste and for polyethylene and Silo 3 waste formulations is shown in Table 4.21 along with the TCLP and UTS concentration limits. All polyethylene encapsulated Silo 3 waste formulations were within TCLP concentration limits and, with the exception of batch F9, were within UTS criteria. 
Table 4.20. Summary of Processibility Testing with Polyethylene and Silo 3 Actual Waste.

\begin{tabular}{|c|c|c|c|c|}
\hline \multirow[t]{2}{*}{ Batch } & \multicolumn{2}{|c|}{ Waste Loading } & \multirow[t]{2}{*}{ Additives } & \multirow[t]{2}{*}{ Cycle Time } \\
\hline & Nominal & Actual $^{(\mathrm{a})}$ & & \\
\hline F9 & 50 wt \% & $48 \mathrm{wt} \%$ & none & $41.7 \sec ^{(\mathbf{b})}$ \\
\hline F10 & 50 wt\% & 45 wt \% & $2.5 \% \mathrm{Na}_{2} \mathrm{~S}$ (dried) & $58.6 \mathrm{sec}^{(\mathrm{b})}$ \\
\hline F11 & 40 wt $\%$ & 28 wt $\%$ & none & $25.9 \mathrm{sec}$ \\
\hline F12 & $40 \mathrm{wt} \%$ & $38 \mathrm{wt} \%$ & $2 \% \mathrm{Na}_{2} \mathrm{~S}$ (dried) & $30.5 \mathrm{sec}$ \\
\hline F13 & 60 wt\% & 49 wt $\%$ & none & $1 \mathrm{~min} 5 \mathrm{sec}$ \\
\hline F14 & $60 \mathrm{wt} \%$ & 60 wt\% & $\begin{array}{l}3 \% \mathrm{Na}_{2} \mathrm{~S} \text { (dried) } \\
4 \% \text { proprietary additive }\end{array}$ & $1 \min 12 \sec ^{(c)}$ \\
\hline
\end{tabular}

(a) estimate based on collection of waste dispersed while processing

(b) based on two replicates

(c) based on four replicates

Table 4.21. TCLP Leach Results (mg/l) for LDPE and Silo 3 Waste Forms.

\begin{tabular}{|c|c|c|c|c|c|c|}
\hline Composition & As & $\mathbf{B a}$ & Cd & $\mathrm{Cr}$ & $\mathbf{P b}$ & Se \\
\hline TCLP limit & 5.0 & 100 & 1.0 & 5.0 & 5.0 & 1.0 \\
\hline UTS limit & 5.0 & 7.6 & 0.19 & 0.86 & 0.75 & 0.16 \\
\hline Silo 3 waste (untreated/baseline) $)^{(a)}$ & 9.444 & $\mathbf{n d}^{(\mathbf{b})}$ & 0.2492 & 3.054 & nd & 2.638 \\
\hline $\begin{array}{l}\text { F9; } 50 \text { wt \% (48 wt \% actual), no } \\
\text { additives }\end{array}$ & 0.1017 & nd & nd & 0.0326 & 2.391 & 0.1116 \\
\hline $\begin{array}{l}\text { F10; } 50 \text { wt \% (45 wt \% actual), } 2.5 \\
\text { wt } \% \mathrm{Na}_{2} \mathrm{~S} \text { (dry) }\end{array}$ & nd & nd & nd & nd & 0.4238 & nd \\
\hline $\begin{array}{l}\text { F11; } 40 \text { wt } \% \text { ( } 28 \text { wt } \% \text { actual), no } \\
\text { additives }\end{array}$ & 0.0756 & nd & 0.0030 & nd & 0.0993 & nd \\
\hline $\begin{array}{l}\text { F12; } 40 \text { wt \% (38 wt \% actual), } 2 \\
\text { wt } \% \mathrm{Na}_{2} \mathrm{~S} \text { (dry) }\end{array}$ & 0.0381 & nd & 0.0025 & nd & 0.0699 & nd \\
\hline $\begin{array}{l}\text { F14; } 60 \mathrm{wt} \%,(60 \mathrm{wt} \% \text { actual }), 3 \\
\text { wt } \% \mathrm{Na}_{2} \mathrm{~S}(\mathrm{dry}), 4 \mathrm{wt} \% \text { additive to } \\
\text { enhance mixing }\end{array}$ & 0.2425 & nd & 0.0020 & 0.0290 & 0.0582 & 0.0878 \\
\hline
\end{tabular}

(a) average of 3 separate samples.

(b) nd: below detection limits for ICP (mg/l); As 0.012, Ba 0.00007, Cd 0.0015, Cr 0.004, Pb 0.014, Se 0.037 
Based on this treatability study, the optimal results were obtained processing the Silo 3 waste at a loading of $60 \mathrm{wt} \%$ with $3 \mathrm{wt} \%$ sulfide additive to reduce toxic metal leachability and $4 \mathrm{wt} \%$ proprietary additive to enhance mixing. The selection of the optimal formulation was based largely on processing results since leach testing results were good for all compositions. The best processing results were obtained with batch F14, for which minimal dispersion was noted and no unencapsulated waste was discharged with the product. All test specimens for shipment to FDF and future performance testing by the University of Cincinnati were formulated from this optimal composition: $60 \mathrm{wt} \%$ Silo 3 waste, $33 \mathrm{wt} \%$ polymer, 3 wt\% Na2S additive and $4 \mathrm{wt} \%$ proprietary additive to enhance mixing. Test specimens included nominal $2 \times 4$ in. right cylinders and $2 \times 2 \times 2$ in. cubes for compression testing. Ten replicates of each of these sample types were prepared. Samples for leach testing included (5) replicates of nominal 1x1 in. right cylinders (ALT), 1x2 in. right cylinders for shrinking core leach tests and $315 \mathrm{~g}$ of TCLP pellets, sufficient for 3 replicate TCLP tests. TCLP specimens were uniform right cylindrical pellets with a maximum dimension of $9.5 \mathrm{~mm}$, as specified in the TCLP protocol. A photograph of LDPE and Silo 3 waste form specimens prepared for shipment to FDF is shown in Figure 4.7.

Dimensions and calculated waste form densities for each sample are summarized in Tables 4.22 - 4.25. The calculated densities vary slightly between a low of $1.50 \mathrm{~g} / \mathrm{cm}^{3}$ for $2 \times 2 \times 2$ in. cubes to $1.54 \mathrm{~g} / \mathrm{cm}^{3}$ for $1 \times 2$ in. right cylinders. The variation between densities for different sample types is a function of the sample molding method for which slightly different compressive forces were used. The same trend was noted in waste form densities calculated for both Silo 1 surrogate and Silo 1 actual waste. Small deviations and percent errors are observed between replicates for each sample type indicating excellent product homogeneity.

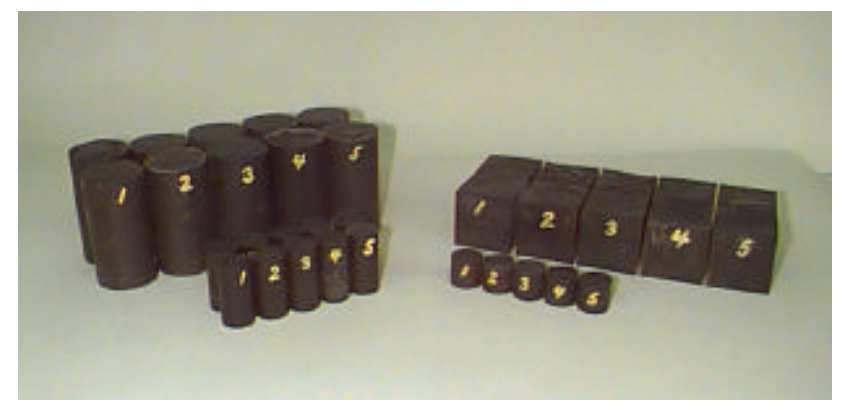

Figure 4.7. LDPE and Silo 3 Waste Form Specimens Prepared for FDF. 
Table 4.22. LDPE Encapsulated Silo 3 Waste $2 \times 4$ in. Cylindrical Specimens.

\begin{tabular}{|c|c|c|c|c|c|}
\hline Sample & $\begin{array}{c}\text { Weight } \\
\text { (g) }\end{array}$ & $\begin{array}{c}\text { Height } \\
(\mathrm{cm})\end{array}$ & $\begin{array}{c}\text { Diameter } \\
(\mathbf{c m})\end{array}$ & $\begin{array}{c}\text { Volume } \\
\left(\mathrm{cm}^{3}\right)\end{array}$ & $\begin{array}{l}\text { Density } \\
\left(\mathrm{g} / \mathbf{c m}^{3}\right)\end{array}$ \\
\hline 1 & 288.35 & 9.47 & 5.06 & 190.49 & 1.51 \\
\hline 2 & 291.30 & 9.61 & 5.05 & 192.13 & 1.52 \\
\hline 3 & 307.71 & 9.65 & 5.16 & 201.93 & 1.52 \\
\hline 4 & 297.25 & 9.65 & 5.09 & 195.87 & 1.52 \\
\hline 5 & 294.60 & 9.54 & 5.09 & 194.23 & 1.52 \\
\hline 6 & 290.91 & 9.61 & 5.10 & 196.36 & 1.48 \\
\hline 7 & 286.29 & 9.38 & 5.06 & 188.22 & 1.52 \\
\hline 8 & 288.79 & 9.40 & 5.10 & 191.48 & 1.51 \\
\hline 9 & 292.48 & 9.47 & 5.10 & 193.56 & 1.51 \\
\hline \multirow[t]{2}{*}{10} & 286.11 & 9.41 & 5.07 & 189.64 & 1.51 \\
\hline & & & & $\begin{array}{r}\text { Mean } \\
\text { Std. Dev. } \\
2 o ́ \\
\text { \% Error } \\
\end{array}$ & $\begin{array}{c}1.51 \\
0.011 \\
0.008 \\
0.53 \\
\end{array}$ \\
\hline
\end{tabular}

Table 4.23. LDPE Encapsulated Silo 3 Waste 1x1 in. Cylindrical Specimens.

\begin{tabular}{|c|c|c|c|c|c|}
\hline Sample & $\begin{array}{c}\text { Weight } \\
\text { (g) }\end{array}$ & $\begin{array}{c}\text { Height } \\
(\mathrm{cm})\end{array}$ & $\begin{array}{c}\text { Diameter } \\
(\mathbf{c m})\end{array}$ & $\begin{array}{c}\text { Volume } \\
\left(\mathrm{cm}^{3}\right)\end{array}$ & $\begin{array}{l}\text { Density } \\
\left(\mathrm{g} / \mathbf{c m}^{3}\right)\end{array}$ \\
\hline 1 & 19.31 & 2.42 & 2.57 & 12.55 & 1.54 \\
\hline 2 & 18.90 & 2.40 & 2.58 & 12.56 & 1.50 \\
\hline 3 & 19.37 & 2.48 & 2.58 & 12.93 & 1.50 \\
\hline 4 & 18.96 & 2.41 & 2.58 & 12.57 & 1.51 \\
\hline \multirow[t]{5}{*}{5} & 19.52 & 2.41 & 2.57 & 12.51 & 1.56 \\
\hline & & & & Mean & 1.52 \\
\hline & & & & Std. Dev. & 0.024 \\
\hline & & & & $2 o ́$ & 0.029 \\
\hline & & & & $\%$ Error & 1.92 \\
\hline
\end{tabular}


Table 4.24. LDPE Encapsulated Silo 3 Waste 1x2 in. Cylindrical Specimens.

\begin{tabular}{|c|c|c|c|c|c|}
\hline Sample & $\begin{array}{c}\text { Weight } \\
\text { (g) }\end{array}$ & $\begin{array}{c}\text { Height } \\
\text { (cm) }\end{array}$ & $\begin{array}{c}\text { Diameter } \\
(\mathbf{c m})\end{array}$ & $\begin{array}{c}\text { Volume } \\
\left(\mathrm{cm}^{3}\right)\end{array}$ & $\begin{array}{l}\text { Density } \\
\left(\mathrm{g} / \mathrm{cm}^{3}\right)\end{array}$ \\
\hline 1 & 40.08 & 5.06 & 2.56 & 26.10 & 1.54 \\
\hline 2 & 39.41 & 5.02 & 2.56 & 25.87 & 1.52 \\
\hline 3 & 40.47 & 5.14 & 2.56 & 26.40 & 1.53 \\
\hline 4 & 41.36 & 5.23 & 2.56 & 26.82 & 1.54 \\
\hline 5 & 40.38 & 5.17 & 2.54 & 26.22 & 1.54 \\
\hline 6 & 40.75 & 5.13 & 2.55 & 26.21 & 1.55 \\
\hline 7 & 40.07 & 5.04 & 2.56 & 25.88 & 1.55 \\
\hline 8 & 40.41 & 5.06 & 2.56 & 26.06 & 1.55 \\
\hline 9 & 40.74 & 5.11 & 2.56 & 26.26 & 1.55 \\
\hline \multirow[t]{5}{*}{10} & 40.11 & 5.04 & 2.55 & 25.79 & 1.56 \\
\hline & & & & Mean & 1.54 \\
\hline & & & & Std. Dev. & 0.010 \\
\hline & & & & $20 ́$ & 0.007 \\
\hline & & & & $\%$ Error & 0.46 \\
\hline
\end{tabular}


Table 4.25. LDPE Encapsulated Silo 3 Waste 2x2x2 in. Cubic Specimens.

\begin{tabular}{|c|c|c|c|c|c|c|}
\hline Sample & $\begin{array}{c}\text { Weight } \\
\text { (g) }\end{array}$ & $\begin{array}{c}\text { Side A } \\
(\mathrm{cm})\end{array}$ & $\begin{array}{c}\text { Side B } \\
(\mathrm{cm})\end{array}$ & $\begin{array}{c}\text { Side C } \\
(\mathrm{cm})\end{array}$ & $\begin{array}{c}\text { Volume } \\
\left(\mathrm{cm}^{3}\right)\end{array}$ & $\begin{array}{l}\text { Density } \\
\left(\mathrm{g} / \mathrm{cm}^{3}\right)\end{array}$ \\
\hline 1 & 192.21 & 5.11 & 5.07 & 5.05 & 130.70 & 1.47 \\
\hline 2 & 187.57 & 5.02 & 5.00 & 5.01 & 125.73 & 1.49 \\
\hline 3 & 189.08 & 5.03 & 5.07 & 4.98 & 127.13 & 1.49 \\
\hline 4 & 192.32 & 5.06 & 5.06 & 4.97 & 127.32 & 1.51 \\
\hline 5 & 190.56 & 5.04 & 5.03 & 5.01 & 126.88 & 1.50 \\
\hline 6 & 195.27 & 5.03 & 5.04 & 5.02 & 127.27 & 1.53 \\
\hline 7 & 193.12 & 5.07 & 5.06 & 5.09 & 130.38 & 1.48 \\
\hline 8 & 193.75 & 5.07 & 5.04 & 5.03 & 128.68 & 1.51 \\
\hline 9 & 192.98 & 5.10 & 5.07 & 5.02 & 129.65 & 1.49 \\
\hline \multirow[t]{5}{*}{10} & 196.24 & 5.10 & 5.08 & 5.03 & 130.24 & 1.51 \\
\hline & & & & & Mean & 1.50 \\
\hline & & & & & Std. Dev & 0.017 \\
\hline & & & & & 20 & 0.012 \\
\hline & & & & & \% Error & 0.81 \\
\hline
\end{tabular}

\subsubsection{SPC Microencapsulation of Silo 3 Actual Waste}

Similar to Silo 1 formulation testing, Silo 3 waste was processed with SPC by adding waste to molten SPC until mixability limits based on viscosity and homogeneity constraints were reached. Maximum waste loading based on mixability was $47 \mathrm{wt} \%$, although alternative mixers may enable higher waste loadings to be achieved. Additional samples were prepared at waste loadings of 40 and $30 \mathrm{wt} \%$ to determine effect of waste loading on TCLP performance. All three waste loadings were processed a second time with addition of $7 \%$ additive based on total weight of Silo 3 in the formulation (to ensure adequate mixability, 45 wt \% waste plus additive was used rather than $47 \mathrm{wt} \%$ waste). TCLP test specimens were prepared from each formulation to determine an optimum formulation based on leach performance.

TCLP leachates for SPC encapsulated Silo 3 formulations were analyzed for $\mathrm{As}, \mathrm{Cd}, \mathrm{Cr}$, $\mathrm{Pb}$, and Se. All leachate samples were below current TCLP allowable concentrations, and all were below UTS levels, except for Se at the highest Silo 3 waste loadings (45 and 47 wt\%), as shown in Table 4.26. The "optimal" waste loading for these samples was therefore determined 
to contain 40 wt \% Silo 3 waste, $57.2 \mathrm{wt} \% \mathrm{SPC}, 2.8 \mathrm{wt} \% \mathrm{Na}_{2} \mathrm{~S}$ additive (7\% of Silo 3 weight). Additive, while not required to pass TCLP for this waste sample, was included as a safety measure to ensure adequate performance in the event localized "hot spots" of high metal concentrations are encountered in treatment of actual waste.

SPC/Silo 3 samples for shipment to FDF were prepared as two $7000 \mathrm{~g}$ batches using the six-liter resistance heated mixer described earlier. Samples prepared included ten $2 \times 2 \times 2$ in. cubes, ten $2 \times 4$ in. cylinders, ten $1 \times 2$ cylinders, five $1 \times 1$ in. cylinders, and three sets of TCLP pellets at a weight of $105 \mathrm{~g}$ each. A photograph of SPC and Silo 3 waste form specimens prepared for shipment to FDF is shown in Figure 4.8. Density data for individual samples is given in Tables 4.27 - 4.30. Mean weighted density of Silo 3 waste forms was $1.99 \mathrm{~g} / \mathrm{cm}^{3}$.

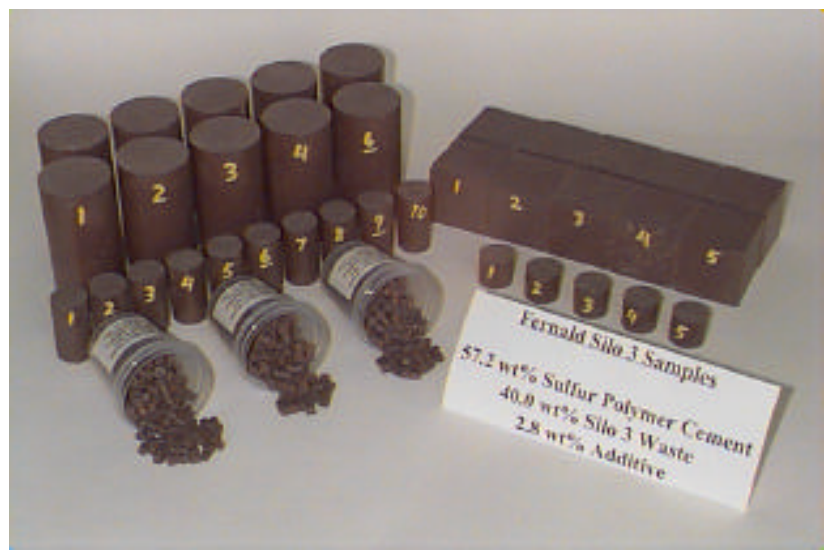

Figure 4.8. SPC and Silo 3 Waste Form Specimens Prepared for FDF.

Table 4.26. TCLP Concentrations (mg/l) for SPC/Silo 3 Test Formulations.

\begin{tabular}{|l|c|c|c|c|c|c||}
\hline Composition & As & Ba & Cd & Cr & Pb & Se \\
\hline \hline TCLP limit & 5.0 & 100 & 1.0 & 5.0 & 5.0 & 1.0 \\
\hline UTS limit & 5.0 & 7.6 & 0.19 & 0.86 & 0.75 & 0.16 \\
\hline \hline $\begin{array}{l}\text { Silo 3 waste } \\
\text { (untreated/baseline) }\end{array}$ & 9.444 & nd & 0.2492 & 3.054 & nd & 2.638 \\
\hline 30 wt\% & 0.373 & nd & 0.0046 & 0.0913 & 0.039 & nd \\
\hline 30 wt\%+ 2.8 wt\% additive & 0.473 & nd & nd & 0.0162 & 0.029 & nd \\
\hline 40 wt\% & 0.695 & nd & 0.0068 & 0.1587 & 0.049 & nd \\
\hline 40 wt\% + 2.8 wt\% additive & 0.861 & nd & 0.0247 & nd & 0.016 & 0.168 \\
\hline 47 wt $\%$ & 1.573 & nd & 0.0038 & 0.1307 & 0.048 & 0.337 \\
\hline 45 wt $\%+2.8$ wt $\%$ additive & 0.868 & nd & 0.0300 & 0.0128 & 0.027 & 0.210 \\
\hline
\end{tabular}

nd: below detection limits for ICP (mg/l); As 0.012, Ba 0.00007, Cd 0.0015, Cr 0.004, Pb 0.014, Se 0.037 
(a) average of 3 separate samples.

Table 4.27. SPC Encapsulated Silo 3 Waste 2x4 in. Cylindrical Specimens.

\begin{tabular}{|c|c|c|c|c|c|}
\hline Sample & $\begin{array}{c}\text { Weight } \\
\text { (g) }\end{array}$ & $\begin{array}{c}\text { Height } \\
(\mathrm{cm})\end{array}$ & $\begin{array}{c}\text { Diameter } \\
(\mathbf{c m})\end{array}$ & $\begin{array}{c}\text { Volume } \\
\left(\mathrm{cm}^{3}\right)\end{array}$ & $\begin{array}{l}\text { Density } \\
\left(\mathrm{g} / \mathrm{cm}^{3}\right)\end{array}$ \\
\hline 1 & 430.37 & 10.08 & 5.25 & 217.93 & 1.97 \\
\hline 2 & 430.54 & 10.06 & 5.25 & 217.39 & 1.98 \\
\hline 3 & 429.96 & 10.07 & 5.25 & 218.08 & 1.97 \\
\hline 4 & 431.64 & 10.08 & 5.25 & 218.04 & 1.98 \\
\hline 6 & 426.62 & 10.04 & 5.25 & 217.00 & 1.97 \\
\hline 7 & 433.80 & 10.07 & 5.25 & 217.89 & 1.99 \\
\hline 8 & 434.62 & 10.08 & 5.25 & 218.26 & 1.99 \\
\hline 9 & 432.91 & 10.06 & 5.25 & 217.88 & 1.99 \\
\hline 10 & 433.44 & 10.06 & 5.25 & 218.16 & 1.99 \\
\hline \multirow[t]{2}{*}{11} & 433.53 & 10.08 & 5.25 & 218.41 & 1.98 \\
\hline & & & & $\begin{array}{r}\text { Mean } \\
\text { Std. Dev. } \\
2 o ́ \\
\text { \% Error }\end{array}$ & $\begin{array}{c}1.98 \\
0.008 \\
0.006 \\
0.29\end{array}$ \\
\hline
\end{tabular}

Table 4.28. SPC Encapsulated Silo 3 Waste 1x1 in. Cylindrical Specimens.

\begin{tabular}{|c|c|c|c|c|c|}
\hline Sample & $\begin{array}{c}\text { Weight } \\
\text { (g) }\end{array}$ & $\begin{array}{c}\text { Height } \\
\text { (cm) }\end{array}$ & $\begin{array}{c}\text { Diameter } \\
(\mathbf{c m})\end{array}$ & $\begin{array}{c}\text { Volume } \\
\left(\mathrm{cm}^{3}\right)\end{array}$ & $\begin{array}{l}\text { Density } \\
\left(\mathrm{g} / \mathrm{cm}^{3}\right)\end{array}$ \\
\hline 1 & 26.41 & 2.45 & 2.61 & 13.16 & 2.01 \\
\hline 2 & 26.07 & 2.43 & 2.61 & 13.04 & 2.00 \\
\hline 3 & 26.34 & 2.44 & 2.61 & 13.11 & 2.01 \\
\hline 4 & 26.40 & 2.45 & 2.62 & 13.16 & 2.01 \\
\hline \multirow[t]{2}{*}{5} & 25.74 & 2.42 & 2.61 & 12.97 & 1.98 \\
\hline & & & & $\begin{array}{r}\text { Mean } \\
\text { Std. Dev. } \\
20 \\
\text { \% Error }\end{array}$ & $\begin{array}{c}2.00 \\
0.009 \\
0.009 \\
0.47\end{array}$ \\
\hline
\end{tabular}


Table 4.29. SPC Encapsulated Silo 3 Waste 1x2 in. Cylindrical Specimens.

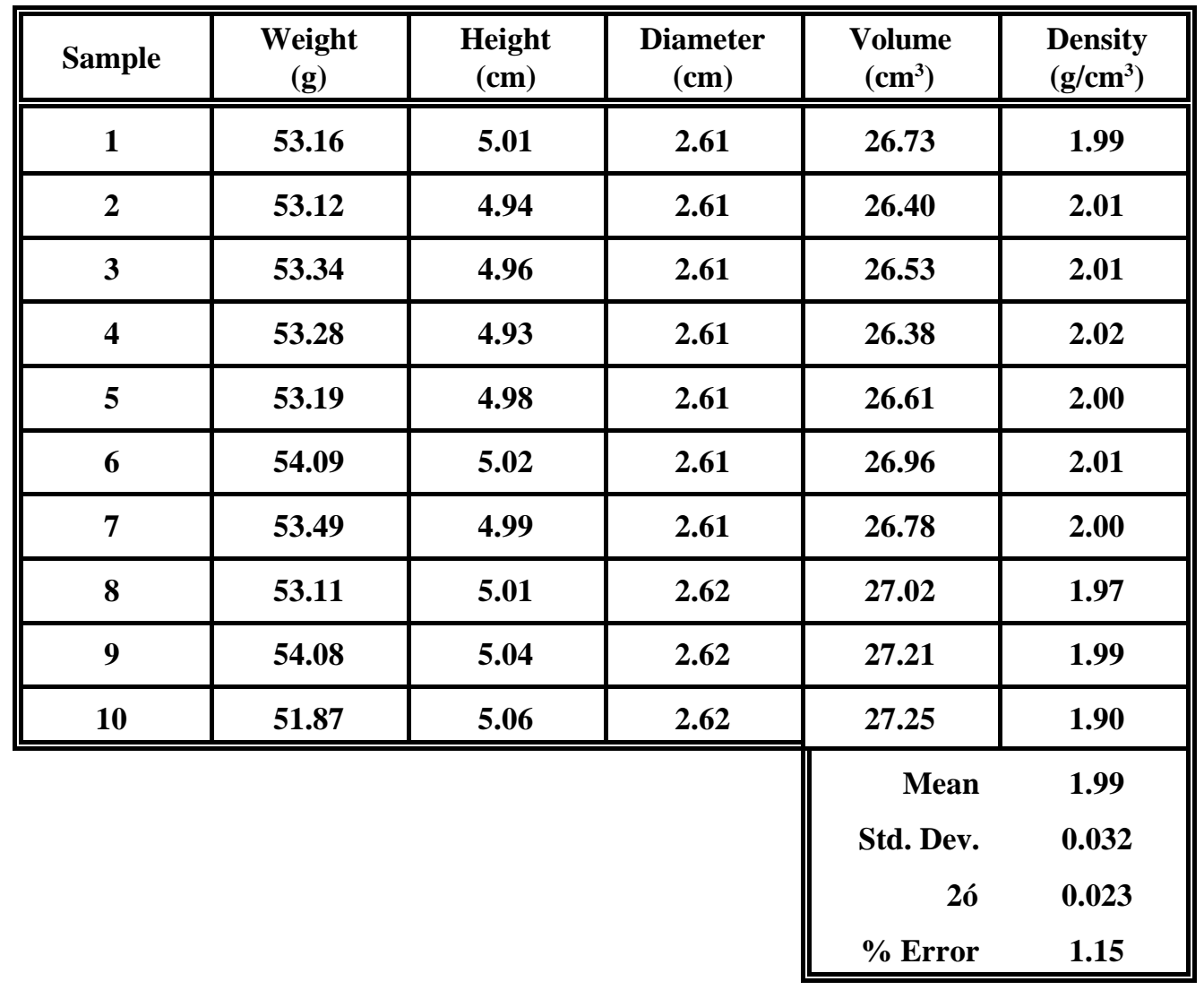


Table 4.30. SPC Encapsulated Silo 3 Waste $2 \times 2 \times 2$ in. Cubic Specimens.

\begin{tabular}{|c|c|c|c|c|c|c|}
\hline Sample & $\begin{array}{c}\text { Weight } \\
\text { (g) }\end{array}$ & $\begin{array}{c}\text { Side A } \\
(\mathrm{cm})\end{array}$ & $\begin{array}{c}\text { Side B } \\
(\mathbf{c m})\end{array}$ & $\begin{array}{c}\text { Side C } \\
(\mathbf{c m})\end{array}$ & $\begin{array}{c}\text { Volume } \\
\left(\mathrm{cm}^{3}\right)\end{array}$ & $\begin{array}{l}\text { Density } \\
\left(\mathrm{g} / \mathrm{cm}^{3}\right)\end{array}$ \\
\hline 1 & 259.90 & 5.07 & 5.02 & 5.08 & 129.52 & 2.01 \\
\hline 2 & 258.02 & 5.07 & 4.99 & 5.07 & 128.48 & 2.01 \\
\hline 3 & 258.10 & 5.08 & 5.01 & 5.08 & 129.07 & 2.00 \\
\hline 4 & 262.57 & 5.08 & 5.09 & 5.07 & 131.16 & 2.00 \\
\hline 5 & 260.79 & 5.08 & 5.01 & 5.07 & 129.33 & 2.02 \\
\hline 6 & 262.45 & 5.07 & 5.07 & 5.08 & 130.64 & 2.01 \\
\hline 7 & 264.32 & 5.07 & 5.09 & 5.07 & 130.83 & 2.02 \\
\hline 8 & 263.57 & 5.07 & 5.10 & 5.07 & 131.10 & 2.01 \\
\hline 9 & 256.28 & 5.07 & 4.99 & 5.08 & 128.48 & 1.99 \\
\hline \multirow[t]{2}{*}{10} & 256.39 & 5.08 & 5.00 & 5.06 & 128.55 & 1.99 \\
\hline & & & & & $\begin{array}{r}\text { Mean } \\
\text { Std. Dev. } \\
20 \\
\text { \% Error }\end{array}$ & $\begin{array}{c}2.01 \\
0.008 \\
0.006 \\
0.29\end{array}$ \\
\hline
\end{tabular}

\subsection{CONCLUSIONS}

Treatability studies were conducted for low-density polyethylene and sulfur polymer microencapsulation of Fernald Silo 1 and 3 wastes. Objectives were to determine whether the Fernald wastes were amenable to treatment by microencapsulation using these BNL developed thermoplastics and to develop optimum treatment formulations. Success was based on consideration of processing results and waste form performance screening tests. Testing of waste form performance was based on leach tests conducted in accordance with the TCLP. Waste form test samples at an optimized formulation were fabricated and sent to FDF for more comprehensive performance testing by the University of Cincinnati. Samples included ten $2 \times 2 \times 2$ in. cubes and ten $2 \times 4$ in. right cylinders for compression testing, ten $1 \times 1$ in. right cylinders and ten $1 \times 2$ in. cylinders for leach testing, and three $100 \mathrm{~g}$ product samples for TCLP testing.

\section{$\underline{\text { Silo } 1}$}

Treatability work for Fernald Silo 1 waste involved formulation development using a 
surrogate and feasibility processing and sample preparation with the actual wastes. Polyethylene microencapsulation processing of Silo 1 surrogate was performed by kinetic mixing at waste loadings of 30 and $50 \mathrm{wt} \%$ and moisture contents of zero or $30 \mathrm{wt} \%$. Metal binding additive was also tested at $2.5,3.5$, and $7.5 \mathrm{wt} \%$ to reduce leachability of toxic metals. A constant batch size of $2 \mathrm{~kg}$ was used. Processing results under all conditions were successful although cycle times were greater for batches containing $30 \mathrm{wt} \%$ moisture, as expected. Poorer leach results were obtained from batches processed with wet surrogate than with dry surrogate. This was attributed to a reaction of the metal binding additive with non-RCRA metals in the surrogate. The optimal formulations resulted in TCLP leach results less than the proposed, more stringent, UTS limits for all RCRA metals. These compositions were dry surrogate at a waste loading of $50 \mathrm{wt} \%$ with low-density polyethylene and either 2.5 or 3.5 wt \% additive. Polyethylene and Silo 1 surrogate waste form specimens had densities ranging from 1.28 to $1.44 \mathrm{~g} / \mathrm{cm}^{3}$. The variation in density is due to the molding method but low errors in replicate sample densities indicated excellent product homogeneity.

Polyethylene processing of the Silo 1 actual waste was performed by extrusion due to radiological concerns with the waste. Since extrusion is a continuous process, no additives were included to reduce processing complexity. The waste loading was maintained at 50 wt $\%$. Feasibility processing was successful. Waste form performance screening tests were not performed but a complete set of waste form specimens were prepared for FDF and analysis by UC.

Sulfur polymer microencapsulation of Silo 1 surrogate was performed using a small laboratory-scale mixer. SP processing requires the use of dry materials so the surrogate was dried prior to formulation development. Waste loadings of 30, 40, 50 and 60 wt\% were processed in $200 \mathrm{~g}$ batches with and without 2.1, 2.8, 3.5, and 4.2 wt\% metal binding additive. Additionally, batches at $30 \mathrm{wt} \%$ surrogate with 3 and $4.5 \mathrm{wt} \%$ additive, and $50 \mathrm{wt} \%$ surrogate with 5 and $7.5 \mathrm{wt} \%$ additive were processed. From a processing standpoint, viscosity is the limiting factor in maximizing the waste loading. For the Silo 1 surrogate, all processing results were successful. Higher loadings are achievable but waste form leaching would be sacrificed resulting in non-acceptable TCLP results. The optimal formulation resulted in TCLP leach results below the current TCLP Pb concentration limit but above the UTS limit. This composition was $40 \mathrm{wt} \%$ surrogate with $6 \mathrm{wt} \%$ additive. Sulfur polymer and Silo 1 surrogate had a mean waste form density of $2.12 \mathrm{~g} / \mathrm{cm}^{3}$.

Sulfur polymer processing of the Silo 1 actual waste was successful. No processing difficulties were encountered. The final formulation was slightly different than the optimal composition determined with the surrogate due to a measuring error. This composition was $43 \mathrm{wt} \%$ Silo 1 actual waste with $6.4 \mathrm{wt} \%$ additive. Waste form performance screening tests were not performed with the actual waste but a complete set of waste form specimens were prepared for FDF and analysis by $\mathrm{UC}$. 
$\underline{\text { Silo } 3}$

Formulation development and feasibility processing were both performed with Silo 3 actual waste since no surrogate was available. Treatability work for polyethylene microencapsulation was conducted using kinetic mixing in $2 \mathrm{~kg}$ batch sizes. Waste loadings of 40, 50 and 60 wt\% were processed using the as-received waste which had a measured moisture content of $3.85 \%$. Processing difficulties were encountered due to the fine particle size of the waste. Some waste material did not become encapsulated while mixing and was subsequently discharged from the mixer unencapsulated. This was remedied upon the inclusion of a proprietary additive to reduce dispersibility and enhance mixing. The optimal formulation was a waste loading of 60 wt\% Silo 3 waste with 3 wt\% $\mathrm{Na}_{2} \mathrm{~S}$ metal binding additive and $4 \%$ proprietary additive. At this formulation, processing results were successful and waste form leach results were significantly less than the UTS metal concentration limits. Polyethylene and Silo 3 waste form specimens had densities ranging from 1.50 to $1.54 \mathrm{~g} / \mathrm{cm}^{3}$. The variation in density is due to the molding method but low errors in replicate sample densities indicated excellent product homogeneity. A complete set of waste form specimens were prepared for FDF and analysis by UC.

Sulfur polymer microencapsulation of Silo 3 actual waste was performed in $200 \mathrm{~g}$ batches using a small laboratory-scale mixer. No processing difficulties were experienced but the maximum waste loading was reached at $47 \mathrm{wt} \%$ based on mixability limitations. During formulation development, waste loadings of 30, 40 and $45 \mathrm{wt} \%$ dry waste were attempted with and without the inclusion of $7 \% \mathrm{Na}_{2} \mathrm{~S}$ metal binding additive (based on dry weight of surrogate in each batch). The optimal formulation was $40 \mathrm{wt} \%$ Silo 3 waste with $2.8 \mathrm{wt} \%$ additive (7\% of waste quantity). Waste form leach results were all below TCLP limits and UTS limits except for Se which was borderline. Sulfur polymer and Silo 3 waste forms had a mean waste form density of $1.99 \mathrm{~g} / \mathrm{cm}^{3}$. A complete set of waste form specimens were prepared for FDF and more comprehensive analysis by $\mathrm{UC}$. 


\subsection{REFERENCES}

1. US EPA, "Toxicity Characteristic Leaching Procedure (TCLP)," 40 CFR 261, Appendix II, U.S. Environmental Protection Agency, Washington DC, September 19, 1994.

2. Kalb, P.D. and P. Colombo, "Polyethylene Solidification of Low-Level Wastes, Topical Report," BNL-51867, Brookhaven National Laboratory, Upton, NY, October 1984.

3. Heiser, J.H., Franz, E.M. and Colombo, P., "A Process for Solidifying Sodium Nitrate Waste in Polyethylene," Environmental Aspects of Stabilization and Solidification of Hazardous and Radioactive Wastes, ASTM STP 1O33, Cote and Gilliam (editors), American Society for Testing and Materials, Philadelphia, PA, 1989.

4. Franz, E.M., J.H. Heiser, III, and P. Colombo, "Immobilization of Sodium Nitrate Waste With Polymers, Topical Report," BNL-52081, Brookhaven National Laboratory, Upton, NY, April 1987.

5. Kalb, P.D., J.H. Heiser, III, and P. Colombo, " Polyethylene Encapsulation of Nitrate Salt Wastes: Waste Form Stability, Process Scale-up, and Economics," BNL- 52293, Brookhaven National Laboratory, Upton NY, July 1991.

6. Kalb, P.D., and M. Fuhrmann, "Polyethylene Encapsulation of Single-Shell Tank Wastes," BNL-52365, Brookhaven National Laboratory, Upton, NY, September 1992.

7. Kalb, P.D., J.H. Heiser, and P. Colombo, "Long-Term Durability of Polyethylene for Encapsulation of Low-Level Radioactive, Hazardous, and Mixed Wastes," Emerging Technologies in Hazardous Waste Management III, D.W. Tedder and R.G. Pohland, eds., American Chemical Society Symposium Series 518, Washington, D.C., 1993.

8. Kalb, P.D., J.W. Adams, M. Meyer, and H. Holmes Burns, "Thermoplastic Encapsulation Treatability Study for a Mixed Waste Incinerator Off-Gas Scrubbing Solution," Stabilization and Solidification of Hazardous, Radioactive and Mixed Wastes, 3rd Vol., ASTM STP-1240, American Society for Testing and Materials, W. Conshohocken, PA, 1996.

9. Adams, J.W., and P.D. Kalb, "Thermoplastic Stabilization Treatability Study for a Chloride, Sulfate and Nitrate Salts Mixed Waste Surrogate," American Chemical Society, D.W. Tedder and R.G. Pohland, eds., in press.

10. Kalb, P.D., and P.R. Lageraaen, "Polyethylene Encapsulation Full-Scale Technology Demonstration," BNL-52478, Brookhaven National Laboratory, Upton, NY, 1995.

11. Kalb, P.D., and P.R. Lageraaen, "Full-Scale Technology Demonstration of a Polyethylene Encapsulation Process for Radioactive, Hazardous, and Mixed Wastes," Journal of Environmental Science and Health, Vol. A31, No. 7, pp. 1767-1780, 1996. 
12. Lageraaen, P.R., B.R. Patel, P.D. Kalb, and J.W. Adams, "Treatability Studies for Polyethylene Encapsulation of INEL Low-Level mixed Wastes," BNL-62620, Brookhaven National Laboratory, Upton, NY, October 1995.

13. Kalb, P.D. and P. Colombo, "Composition and Process for the Encapsulation and Stabilization of Radioactive, Hazardous, and Mixed Wastes," U.S. Patent Nos. 5,649,323, July 15, 1997, and 5,732,364, March 24,1998.

14. Sullivan, T.A., and W.C. McBee, Development and Testing of Superior Sulfur Concretes, Report of Investigations 8160, Bureau of Mines, U.S. Department of the Interior, Washington, D.C., 1976.

15. Personal communication, Hugh Harbour, Martin Chemicals, Odessa, TX, Feb. 5, 1990.

16. Colombo, P., P.D. Kalb, and J.H. Heiser, "Process for the Encapsulation and Stabilization of Radioactive, Hazardous, and Mixed Wastes,” U.S. Patent No. 5,678,234, Oct. 14, 1997.

17. "Sulphur Concrete...A New Construction Material Comes of Age", Sulphur Research and Development, Vol. 2, 1979.

18. "SCRETE Sulfur Concrete", Manufacturer's Data Sheet, Chevron Chemical Co., San Francisco, CA.

19. Kalb, P.D. and P. Colombo, "Modified Sulfur Cement Solidification of Low-Level Wastes, " BNL-51239, Brookhaven National Laboratory, Upton, NY, October 1985.

20. Kalb, P.D., J.H. Heiser, and P. Colombo, "Modified Sulfur Cement Encapsulation of Mixed Waste Contaminated Incinerator Fly Ash," Waste Management, Vol. 11, pp. 147-153, 1991.

21. Kalb, P.D., L.W. Milian, S.P. Yim, R.S. Dyer, and W.R. Michaud, "Treatability Study on the use of By-Product Sulfur in Kazakstan for the Stabilization of Hazardous and Radioactive Wastes," Proceedings of the American Chemical Society Symposium on Emerging Technologies in Hazardous Waste Management IX, Pittsburgh, PA, Sept. 15-17, 1997.

22. Kalb, P.D., J.H. Heiser, R. Pietrzak, and P. Colombo, "Durability of Incinerator Ash Waste Encapsulated in Modified Sulfur Cement," Proceedings of the 1991 Incineration Conference, Knoxville, TN, May 1991. 